\title{
Robotización/automatización y despido objetivo por causas técnicas (Art. 52 c ET)*
}

\section{Robotization/automation and objective dismissal for technical reasons (Art. 52 c ET)}

\author{
Ángel Jurado Segovia* \\ Profesor Ayudante Doctor (acreditado a Profesor Titular) \\ Universidad Complutense de Madrid
}

ORCID ID: 0000-0002-2612-9967

Recibido: 5/06/2020

Aceptado: 3/07/2020

doi: https://doi.org/10.20318/labos.2020.5771

Resumen: Una notable repercusión mediática ha tenido la sentencia de un Juzgado de lo Social de las Palmas que, asumiendo como premisa que la robotización comportará una fuerte destrucción del empleo, declaró improcedente un despido -ex art. 52 c) ET- que había sido acometido por la empresa invocando la implantación de un nuevo software que permite automatizar las funciones de la trabajadora despedida. La sentencia se decanta por una interpretación claramente restrictiva, que circunscribe la procedencia de estos despidos a las empresas que atraviesen dificultades. En el presente trabajo, se reseña, en primer lugar, críticamente dicha sentencia, subrayando que la lectura realizada no se ajusta a la letra y espíritu de la norma vigente; $y$, en segundo lugar, se abordan diversas cuestiones en torno a lo que, a juicio del autor, constituye el esquema hermenéutico apropiado en punto al control judicial de estos despidos por "causas técnicas".

Palabras clave: robotización, automatización, despido, causas técnicas, control judicial.

Abstract: $\quad$ A judgment by a Social Court of Las Palmas has had a significant media impact. Assuming that robotization will entail a strong destruction of employment as a premise, the judgment declared unjustified a dismissal -ex art. 52 c) ET- that had been executed invoking the implementation by the company of a new software that automates the functions of the dismissed employee. The judicial decision opts for a clearly restrictive interpretation, which restricts the lawful of these dismissals to companies in difficulty. This paper, firstly, critically reviews the judgment, stressing that its interpretation does not conform to the

\footnotetext{
"El presente estudio ha sido elaborado en el marco del Proyecto I+D+i: "El impacto de la digitalización en las relaciones de trabajo: retos y oportunidades" (Ref.: PID2019-104287RB-I00, Universidad Complutense de Madrid; Investigadores Principales: Francisco Pérez de los Cobos Orihuel y Nuria García Pińeiro), perteneciente a la Convocatoria 2019 del "Marco del Programa Estatal de Generación de Conocimiento y Fortalecimiento Científico y Tecnológico del Sistema de I+D+i y del Programa Estatal de $\mathrm{I}+\mathrm{D}+\mathrm{i}$ orientada a los retos de la sociedad".

angel.jurado78@gmail.com
} 
letter and spirit of the current norm; and, secondly, various issues are addressed around what, in the author's opinion, constitutes the appropriate hermeneutic scheme regarding the judicial control of these dismissals for "technical reasons".

Keywords: robotization, automation, dismissal, technical reasons, judicial control.

\section{Introducción}

La preocupación y el análisis sobre las repercusiones del cambio tecnológico constituyen, en buena medida, un "continuum" en el Derecho del Trabajo. No en balde, la emergencia del Derecho del Trabajo fue una de las respuestas a los profundos cambios tecnológicos que trajo consigo la llamada revolución industrial ${ }^{1}$. Asimismo, en la posterior evolución de la rama jurídico-laboral ha influido, sin duda, la necesidad de preservar su compleja funcionalidad ante las diversas las transformaciones tecnológicas ${ }^{2}$. Bien mirado, lo que se ha producido a lo largo de la historia no ha sido tanto varias revoluciones tecnológicas cuanto una continua evolución tecnológica con un impacto gradual en los sistemas económicos, sociales y jurídicos, sin perjuicio de que los particulares rasgos del cambio tecnológico en curso probablemente le imprimen un mayor calado en comparación con anteriores transformaciones ${ }^{3}$. El avance de la globalización económica y de profundos cambios tecnológicos son fenómenos que, en gran medida, se retroalimentan ${ }^{4}$. La globalización de los mercados se acrecienta gracias a la llamada digitalización de la economía y, a su vez, la globalización comporta que los actuales cambios tecnológicos, por contraste con los precedentes, tengan una incidencia más generalizada en las economías y en los diversos sectores productivos. Y muy unido a lo anterior se presenta otro rasgo de la citada digitalización, cual es la velocidad de los cambios y su continua evolución. Los cambios tecnológicos penetran rápidamente en las diversos sectores económicos y sociales y prácticamente sin solución de continuidad se observan nuevos perfiles de las transformaciones en acto.

Dicho lo anterior, también es cierto que se observa una cierta continuidad en los debates económicos, sociales y, como no podía ser de otro modo, jurídico-laborales que el cambio tecnológico de nuevo cuño pone sobre la mesa. En el análisis de los efectos de la digitalización están notablemente presentes, como lo estuvieron en el análisis de otras transformaciones tecnológicas, cuestiones tales como la de su impacto sobre las capacidades profesionales requeridas en los trabajadores y la de sus efectos sobre los niveles de empleo. La historia ha desmentido en varias ocasiones pronósticos sobre el fuerte descenso del empleo que traerían consigo las innovaciones tecnológicas ${ }^{5} \mathrm{y}$, sin perjuicio de que las características del vigente cambio tecnológico parecen augurar que cada vez más un buen número de tareas se irán automatizando, lo cierto es que en el actual y heterogéneo debate sobre la digitalización y el futuro del trabajo y el empleo ${ }^{6}$ no parece haberse llegado a un consenso

${ }^{1}$ Cfr. ALONSO OLEA, M.: "La revolución industrial y la emergencia del Derecho del Trabajo", Revista de Trabajo, no 32, 1970, pág. 5.

${ }^{2}$ Cfr. CRUZ VILLALÓN, J.: "Las transformaciones de las relaciones laborales ante la digitalización de la economía", Temas Laborales, no 138, 2017, págs. 26 y 27.

${ }^{3}$ Esta perspectiva histórica de análisis en MERCADER UGUINA, J. R.: El futuro del trabajo en la era de la digitalización y la robótica, Valencia, Tirant lo Blanch, 2017, pág. 24 y ss.

${ }^{4}$ Sigo en este punto a CRUZ VILLALÓN, J.: "Las transformaciones...", cit. pág. 15 y ss.

${ }^{5}$ Reflexionando en este sentido, GOERLICH PESET, J. M.: “¿Repensar el derecho del trabajo? Cambios tecnológicos y empleo", Gaceta Sindical, no 27, 2016, pág. 177.

${ }^{6} \mathrm{Al}$ que están contribuyendo organizaciones como la OIT y la Comisión Europea, así como otras instituciones de diversa naturaleza y académicos de varias disciplinas, proyectándose visiones más o menos "tecnopesimistas" o "tecnoptimistas". En la doctrina laboralista, reseñando algunas de estas visiones y pronósticos sobre los efectos del actual cambio tecnológico, véase, entre otros, GOERLICH PESET, J. M.: “¿Repensar...”, cit., pág. 176 y ss.; MERCADER UGUINA, J. R.: El futuro..., cit., pág. 225 y ss.; USHAKOVA, 
claro y amplio sobre cuáles serán los efectos a corto-medio plazo ${ }^{7}$. Y es que no parece que el diagnóstico pueda simplificarse con afirmaciones -que pueden ser consideradas falaces desde el punto de visto económico- del tipo: si las máquinas hacen el trabajo habrá obviamente menos empleo ${ }^{8}$.

Pues bien, en conexión con el debate apuntado, pero asumiendo una perspectiva de análisis jurídico-positiva, el presente trabajo tiene por objeto examinar en qué medida la introducción de innovaciones tecnológicas en la empresa puede justificar la extinción de contratos de trabajo en virtud del art. 52 c) ET y, en particular, de las "causas técnicas" tipificadas en este ámbito. En este sentido, cabe traer a colación que hace no mucho tiempo tuvo una notable repercusión mediática una sentencia dictada por el JS no 10 de Las Palmas, de 23-9-2019 (Procedimiento no 470/2019), que declaró improcedente el despido ex art. 52 c) ET de una trabajadora, habiendo invocado la empresa para acometer tal despido la automatización de las tareas de la misma a través de la implantación de un software o -según terminología empleada en la propia SJS- un "robot" o "bot" informático. La sentencia parece querer presentarse como la respuesta ante una cuestión novedosa, señalando que "la automatización implica la irrupción de algo nuevo, y no el cambio de algo pasado (...)", pues "se pasa de que los trabajadores hagan uso de un instrumento de producción para el desempeño de su trabajo, a que el instrumento de producción haga ese trabajo por sí". Seguramente sea cuestión de matices, pero los propios repertorios de jurisprudencia parecen desmentir que nos encontremos ante algo tan novedoso?. Ciertamente, una ojeada rápida a la doctrina de los tribunales permite establecer, prima facie, una ligazón entre la codificación legal de unas "causas técnicas" y la puesta a disposición de un mecanismo que permite a las empresas acometer ajustes de empleo a raíz de la introducción de innovaciones tecnológicas en los medios o procesos productivos. Así, a modo de ejemplo y sin entrar en los pormenores del caso, se ha entendido que concurrían causas técnicas cuando una empresa de la industria alimentaria adquiere una nueva máquina de selección de vegetales, que opera mediante lectura fotométrica de colores, formas y volúmenes, con una fiabilidad que supera ampliamente la capacidad de selección humana ${ }^{10}$; o en el caso de una empresa del sector de la construcción, que realiza inversiones tecnológicas que permiten que la información obtenida in situ por los topógrafos se traslade, sin necesidad de adicionales intervenciones humanas, al sistema informático de la empresa ${ }^{11}$.

Pues bien, tras estas consideraciones introductorias, en las páginas que siguen se reseña, en primer lugar, con mayor detalle la citada SJS de Las Palmas, en tanto que constituye un buen punto de partida sobre los puntos críticos que presenta la materia objeto de análisis; para, en segundo lugar, esbozar los principales elementos y cuestiones a considerar en cuanto al control judicial de los despidos que, en la línea del supuesto planteado en la citada SJS, se puedan fundamentar en "causas técnicas". Todo ello a la luz, como es obvio, de la regulación vigente, pero resultando inevitables las continuas referencias a los precedentes normativos en esta materia, toda vez que el sentido y alcance de la actual regulación se comprende, en gran parte, como el resultado de una larga y, en buena medida, ambigua evolución legal e interpretativa.

T.: "De la maquina al trabajador y viceversa. Un ensayo sobre la implicación de las nuevas tecnologías en el mundo laboral", Revista internacional y comparada de relaciones laborales y derecho del empleo, $\mathrm{n}^{\circ}$ 1, 2018, pág. 123 y ss.; MONTOYA MEDINA, D.: "Nuevas relaciones de trabajo, disrupción tecnológica y su impacto en las condiciones de trabajo y empleo", Revista de treball, economia i societat, no 92, 2019, pág. 2 y ss.

${ }^{7}$ En esta línea, CRUZ VILLALÓN, J.: “Las transformaciones...”, cit. págs. 18, 19, 30 y 31.

${ }^{8}$ En este sentido, subrayando que detrás de este tipo de argumentos se puede encontrar lo que la ciencia económica conoce como falacia de la cantidad fija de trabajo, consistente en entender que hay una cantidad de trabajo preestablecida, sin tener en cuenta factores como la inversión y la productividad, MERCADER UGUINA, J. R.: El futuro..., cit., pág. 234 y 235.

${ }^{9}$ En esta línea, MERCADER UGUINA, J. R.: "Despido de una administrativa cuyo trabajo ha sido sustituido por un Robot: ¿es posible poner Puertas al Campo", en el blog: El Foro de Labos, disponible en: https:/forodelabos.blogspot.com/2019/10/despidode-una-administrativa-cuyo.html (consulta 21-5-2020).

${ }^{10}$ STSJ Castilla-La Mancha 27-3-2002 (Ro 141/2002).

${ }^{11}$ STSJ Castilla-León 17-12-2009 (Ro 742/2009). 


\section{La SJS no 10 Las Palmas de 23-9-2019: una reseña crítica a la luz de la evolución normativa}

Como se apuntaba, un buen modo de aproximarse a la materia objeto de estudio puede ser partir de la SJS de Las Palmas antes citada, que declaró improcedente el despido ex art. 52 c) ET en un supuesto en que la empresa había implantado un nuevo software que permitía automatizar tareas realizadas por la trabajadora despedida. En particular, y sin perjuicio de posteriores detalles, de los hechos declarados como probados por la sentencia se desprende, en esencia, que: 1) La trabajadora despedida trabajaba a tiempo completo para una empresa, cuya actividad se centra en la gestión turística y hotelera, prestando servicios para otras diversas empresas (unos 500 hoteles aproximadamente). 2) La trabajadora desarrollaba tareas propias de la categoría de oficial de contabilidad, dedicándose, entre otras funciones, a las de cobro y conciliación de facturas impagadas de grandes clientes. 3) La empresa en un momento determinado adquiere "la licencia del software Jidoka" que "es un RPA, acrónimo de Robotic Process Automation", esencialmente "orientado a realizar tareas repetitivas, mecánicas y que varían muy poco en cada iteración" y que en la empresa se destina particularmente a "las tareas de Reclamación de cobros (gestión de cobros) y Compensación de cobros (conciliación de cobros)". El software es capaz de leer la información que remiten los clientes, "verifica si hay reclamaciones pendientes de enviar, descarga informe sobre las facturas pendientes de pago, realiza un tratamiento de datos del cliente y le envía por email el informe generado de reclamación". El software realiza tales tareas "desde las 17:15 hasta 06:00, y los festivos y fines de semana trabaja 24 horas". Pues bien, siendo estos los hechos esenciales, la sentencia fundamenta la declaración de improcedencia del despido en diversos razonamientos jurídicos, que pueden agruparse, en síntesis, en tres bloques de argumentos.

En primer lugar, partiendo de que la empresa invocó en la carta despido causas tanto "productivas" como "organizativas y técnicas"-todas ellas referenciadas, como es sabido, en el ámbito de los arts. 51 y 52 c) ET-, la sentencia descarta que en el caso concreto estuviese justificada la extinción por causas productivas. En efecto, la sentencia niega que quepa apreciar tales causas en la medida que no resulta acreditado ningún "cambio" en torno a los productos o servicios a los que se dedica la empresa y la misma pretende identificar tales causas productivas en datos que apuntan a un declive del mercado turístico en el que se centra su actividad, basándose en meras proyecciones negativas de futuro, pero sin acreditar una causa actual que justifique la concreta decisión extintiva que afectó a la trabajadora. Es más, como elemento para negar que la empresa esté afectada por una causa productiva la sentencia pone de relieve el propio hecho de que la empresa haya adquirido el "robot" para atender al importante volumen de trabajo que generan entre 10 y 15 grandes operadores turísticos que tiene como clientes. Sobre este punto, no siendo el más relevante para las cuestiones que se pretenden abordar en el presente estudio, poco cabe objetar a la SJS comentada, en tanto que, ciertamente, de acuerdo con lo previsto legalmente las causas productivas se ponen en relación con los "cambios" que se produzcan en la "demanda de los productos o servicios que la empresa pretende colocar en el mercado" (art. 51.1 ET); referencia legal muy influenciada por la tradición interpretativa en torno a tales causas, derivándose diferencias pero también concomitancias con las causas "económicas", en el sentido de que en el fondo de la causas productivas laten posibles problemas financieros provocados esencialmente por una reducción de la demanda, que, en todo caso, debe ser real y actual y no meramente hipotética ${ }^{12}$.

En segundo lugar, entrando ya a valorar la posible justificación del despido desde el punto de vista de las causas "técnicas" y "organizativas" también invocadas por la empresa, la sentencia contiene toda una serie de razonamientos que se proyectan sobre las finalidades y funciones del

${ }^{12}$ Cfr. GARCÍA MURCIA, J.: "Las causas de despido colectivo: causas técnicas, organizativas y de producción”, en (GODINO REYES, M. Coord.): Tratado de despido colectivo, Valencia, Tirant lo Blanch, 2016, pág. 12 y ss. 
software implantado por la empresa y sobre las tareas desarrolladas por la trabajadora despedida. El pronunciamiento no parece dudar de que el caso planteado se sitúa más propiamente en el terreno de las causas técnicas, a las que la ley se refiere aludiendo a "cambios (...) en el ámbito de los medios o instrumentos de producción" y, de entrada, no parece objetar -aunque más adelante la sentencia entra en cierta contradicción con ello- que la empresa haya decidido acometer dichos cambios técnicos por razones de costes y de eficiencia empresarial. En este sentido, destaca la resolución judicial que el coste anual del software es muy inferior al de la trabajadora, desarrollando, además, el "bot" un trabajo en términos de horas notablemente superior al de aquélla. Renglón seguido, sin embargo, lo que sí objeta la sentencia es que no haya quedado debidamente probado que como consecuencia de las funciones desarrolladas por el software las tareas que venía desarrollando la trabajadora hayan quedado sustancialmente vacías de contenido. En este punto los razonamientos de la resolución judicial resultan menos sistemáticos, pero la conclusión principal que se extrae es que, si bien se entiende acreditado que el "bot" ha asumido una gran parte de las tareas de reclamación y compensación de cobros, no ocurre lo mismo con el dato alegado por la empresa de que la trabajadora dedicaba más del $97 \%$ de su jornada mensual a dichas tareas y que, por tanto, su trabajo ha quedado reducido de forma muy sustancial. Señala, en este sentido, la sentencia que "no hay ninguna prueba objetiva y sobre todo contrastable y contrastada que permita mantener la conclusión de (...) que la actora dedicaba el 8\% de su jornada mensual a "Gestión de cobros" y el 89,23\% de su jornada mensual a "Conciliación de cobros" (...)"; "no hay aportado a la causa ningún registro (...) en el que se pueda verificar que efectivamente dedicaba esas horas a esas tareas, no hay pericial alguna a este respecto, (...) sólo tenemos afirmaciones de cuya realidad sólo puede creerse pero no verificarse". Y más adelante que: "se parte de que el trabajo de la actora no se elimina al completo, sino sólo en un $70 \%$ de algunas tareas, a saber, de "Compensación de cobros" y "Reclamación de Cobros", y ello por cuanto no se habian dado al 'bot' todos los clientes, sino solo 7 de los 500. Ahora bien, no se encuentra tampoco un estudio sobre cuánto tiempo dedicaba la actora a esos 7 clientes (...) que podría ser un $50 \%$ o un $40 \%$ o incluso un 1,4\% (porcentaje real de 7 respecto a 500). Es cierto que todos los testigos y partes afirman que esos 7 clientes son los que más facturan y por ende los que más trabajo dan, ahora bien, no hay datos numéricos contrastables, con datos subyacentes analizables que permitan un debate sobre la realidad de esos porcentajes, por lo que no cabe, igualmente sino tener por no acreditados tales hechos (...)”.

Estas consideraciones llevan a la sentencia a declarar no probada la causa técnica invocada para despedir, si bien lo que, en puridad, queda patente a través de ellas es lo que cabe considerar como un segundo momento del control judicial sobre estos despidos, en el que se exige la acreditación de la necesaria actualización de los efectos de la causa probada sobre un concreto puesto de trabajo como requisito para justificar el despido ${ }^{13}$ (véase infra 3.1). Como puso de manifiesto la jurisprudencia en su día, "la amortización de puestos de trabajo se ha de concretar en el despido o extinción de los contratos de aquel o aquellos trabajadores a los que afecte el ajuste de producción o de factores productivos que se haya decidido" ${ }^{\text {. }}$. Y, ciertamente, en la doctrina judicial relativa a los despidos por causas técnicas resulta frecuente advertir la centralidad que cobran los elementos fácticos que, a criterio de los tribunales, permiten atestiguar una efectiva amortización del puesto o puestos de trabajo, en el sentido de que los mismos hayan quedado vacíos de su contenido fundamental, aunque puedan subsistir tareas residuales ${ }^{15}$. Y coherentes con ello resultan aquellos otros pronun-

${ }^{13}$ Cfr. DESDENTADO BONETE, A.: “La reforma del despido en el Real Decreto-Ley 10/2010”, en AAVV: La reforma laboral de 2010. Aspectos prácticos, Valladolid, Lex Nova, pág. 90.

${ }^{14}$ STS 14-6-1996 (Ro 3099/1995).

${ }^{15}$ Cfr., entre otras, STSJ Asturias 15-11-2013 (Ro 1829/2013); SSTSJ Galicia 27-1-2015 (Ro 3505/2014) y 19-7-2016 (Ro 921/2016); STSJ Andalucía 17-5-2016 (Ro 1385/2015); STSJ Cataluña 9-6-2016 (Ro 2167/2016); STSJ Madrid 7-2-2019 (Ro 933/2018); STSJ Cataluña 13-12-2019 (Ro 4187/2019). 
ciamientos que declaran la improcedencia de los despidos por entender no acreditado que las innovaciones tecnológicas introducidas hayan tenido una incidencia directa y relevante sobre los puestos ocupados por los trabajadores despedidos ${ }^{16}$. Se trata, obviamente, de una cuestión de prueba y su valoración judicial, se quiera o no, está envuelta de una notable discrecionalidad, lo que puede llevar a una mayor o menor rigurosidad judicial a la hora de exigir datos que evidencien que el cambio tecnológico ha repercutido de modo sustancial en el puesto de trabajo que se pretende suprimir. En el caso de la SJS reseñada, el Magistrado considera insuficientes los datos y elementos probatorios aportados, respecto de lo cual poco más cabe comentar considerando el principio de sana crítica que fundamentalmente asiste a los órganos judiciales en la valoración de las pruebas (art. 218 LEC). Con todo, a la luz del conjunto de razonamientos de la sentencia, lo anterior no resulta incompatible con plantear la hipótesis de si en la formación del criterio del juzgador sobre el fondo del asunto planteado no pesó, tanto o más que cuestiones de prueba, su concepción en torno a la finalidad que cabe atribuir en el ordenamiento laboral vigente a los despidos por causas técnicas.

En efecto, un tercer bloque de argumentaciones las dedica la sentencia a exponer su visión acerca de la ratio legis que subyace en la regulación de estos despidos. En este sentido, tras subrayar que en la calificación de su procedencia o improcedencia se manifiesta un particular conflicto de intereses entre la libertad de empresa y el derecho del trabajo (arts. 38 y $35 \mathrm{CE}$ ), la sentencia sostiene que la simple mejora de la eficiencia empresarial no puede ser el elemento que justifique la inclinación de la balanza a favor de la libertad de empresa. A tal efecto, la sentencia se apoya fundamentalmente en el voto particular de la STS 31-5-2006 (Ro 49/2005), que se apartó del criterio mayoritario en un supuesto de despido por externalización de actividades, centrando su discrepancia en el hecho de entender que la sustitución de la referencia a la "viabilidad" de la empresa por la de "dificultades", operada en el art. 52 c) ET por la reforma laboral de 1997, no había alterado la sustancia de este mecanismo extintivo, que seguía obedeciendo a la "necesidad"-también aludida en el art. 52 c) ET por aquel entonces- de que el despido se presente como la respuesta a acreditados problemas de funcionamiento de la empresa. Partiendo, en efecto, de este entendimiento y realizando también alguna alusión al juicio de razonabilidad de los despidos (véase infra 3.2), y pese a reconocer que con las sucesivas reformas normativas han desaparecido la mayoría de referencias normativas a las que se alude, la SJS de Las Palmas reseñada afirma que la "mayor flexibilización efectuada por el legislador con la reforma de 2012 (...) no exime al empleador del deber de acreditar que real y efectivamente atraviesa por dificultades de cierta entidad para cuya superación es medida adecuada y razonable la extinción de contratos de trabajo, dado que lo contrario implicaria dejar libérrimamente en manos del empresario la opción unilateral por la extinción contractual con el pago de una indemnización inferior a la ordinaria (...).

A mayor abundamiento, la sentencia prosigue engarzando esta concepción de los despidos por causas técnico-organizativas con algunos datos que la misma estima relevantes acerca del impacto de la automatización o robotización, llegando a estimar la resolución judicial que ello "implicará una destrucción de empleos de al menos el $35 \%$ de la población activa", por lo que entiende que "siendo el despido objetivo una forma privilegiada y si se quiere excepcional, de concluir una relación laboral con una indemnización inferior a la ordinaria, no puede calificarse de excepcional, aquella causa que pueda afectar al 35\% de todos los trabajos"; datos que, a juicio del juzgador, "hacen necesaria una reinterpretación del concepto de "causas técnicas" para el despido objetivo". Y, en este sentido, volviendo sobre el caso concreto planteado, se señala que "la introducción de 'bots' en el entorno laboral implica la multiplicación de la productividad (...). Esto es, se erige la mejora de la competitividad como elemento único que justifique el despido, mediante la introducción de 'bots' que automaticen el trabajo, desplazando a la

\footnotetext{
${ }^{16}$ Cfr., entre otras, STSJ Comunidad Valenciana 15-5-2013 (Ro 668/2013); STSJ Cataluña 7-7-2016 (Ro 3107/2016); STSJ Cantabria 31-10-2018 (Ro 590/2018); SSTSJ Andalucía 14-11-2018 (Ro 3648/2017) y 14-2-2019 (Ro 2006/2018); STSJ Madrid 7-10-2019 (Ro 775/2019).
} 
masa laboral humana. Definitivamente, esto no puede ser tenido como una causa justa para un despido objetivo procedente, por cuanto lo contrario implicaria favorecer, so pretexto de la competitividad, la subestimación y minimización del Derecho al Trabajo. La correcta interpretación del art. 52 c) ET, no puede llevarnos a confundir la mera conveniencia empresarial de reducir costes, con la necesidad de superar desajustes entre la fuerza laboral y la oferta. No debe olvidarse que la finalidad de este precepto legal es la de contribuir a ayudar a la empresa que atraviesa dificultades (...), y no la de configurar un sistema de incremento de los beneficios en aquellas empresas que, no atravesando complicación alguna, pretenden acogerse al mismo ante cualquier eventualidad o circunstancia que se produce en su proceso técnico, productivo y de organización, trasladando al trabajador los riesgos de la actividad empresarial y haciendo recaer sobre el mismo cualquier incidencia del mercado (...). [E]n el caso presente no se ha producido un problema o desajuste entre la demanda existente en el mercado y la fuerza laboral existente en la empresa, sino que ha sido la propia empresa, que no tenia problemas previos, la que ha introducido un elemento que ha creado dicho desajuste (...) al adjudicar a un 'bot' el trabajo que antes desempeñaban humanos. Concluyendo, en fin, la sentencia con afirmaciones del siguiente tenor: "la automatización mediante 'bots' o 'robots', con la única excusa de reducir costes para aumentar la competitividad, viene a significar los mismo que reducir el Derecho al Trabajo para aumentar la Libertad de Empresa. Siendo asi por tanto que no puede tenerse por procedente un despido en estos términos, en atención a la interpretación que (...) ha de darse del despido objetivo por causas técnicas (...)".

$\mathrm{Ni}$ que decir tiene que este tercer grupo de argumentos manejados por la SJS reseñada son los que presentan un mayor interés desde el punto de vista de una lectura jurídico-dogmática del mecanismo extintivo ex art. $52 \mathrm{c}$ ) ET, con obvias repercusiones prácticas en los supuestos que se vienen planteando y se seguirán planteando en punto a los cambios tecnológicos introducidos por las empresas y la posibilidad de realizar ajustes de personal de modo procedente. Pues bien, a este respecto, la sentencia reseñada resulta, a mi juicio, bastante criticable en tanto que minusvalora las notables modificaciones normativas que se han ido introduciendo en este terreno, máxime con la reforma laboral de 2012, obviando las finalidades perseguidas con tales modificaciones normativas y decantándose, a la postre, por una suerte de inmovilismo interpretativo que, además, tiene bastante de suplantación del papel del legislador.

En este sentido, bien puede afirmarse que la SJS comentada se alinea con las tesis más restrictivas que, en buena medida, se impusieron sobre la base de ciertos elementos que caracterizaron a las reformas acometidas en esta materia en la década de los 90. Ciertamente, uno de los aspectos relevantes de la reforma laboral de 1994 radicó en una nueva ordenación de los despidos por causas relacionadas con el funcionamiento de las empresas y, entre otros aspectos, destacó que la anterior referencia a causas "económicas y tecnológicas" fuese sustituida por la de causas "económicas, técnicas, organizativas o de producción", con el aparente objetivo de flexibilizar la rígida interpretación que se venía haciendo en el marco normativo anterior, muy anclada en la idea de crisis empresarial ${ }^{17}$. Tal innovación fue acompañada, sin embargo, de otras que, aunque parecían orientadas en esa misma dirección, lo cierto es que en la práctica frustraron, en buena medida, el objetivo de flexibilización e introdujeron altos márgenes de incertidumbre en la calificación de estos despidos ${ }^{18}$. El legislador, utilizando unos términos excesivamente "prolijos y equívocos" "19 añadió al nuevo elenco de causas extintivas un elemento finalista al que debían contribuir los despidos; particularmente, "contribuir

${ }^{17}$ Cfr. DURÁN LÓPEZ, F. “El despido objetivo: causas, forma y efectos”, Revista Española de Derecho del Trabajo, no 100, 2000, pág. 1097.

${ }^{18}$ Cfr. DESDENTADO BONETE, A.: “El despido objetivo económico entre dos reformas: 1994 y 1997”, Relaciones Laborales, Tomo-2, 1998, págs. 445 y 456. En esta misma línea, MONTOYA MELGAR, A.: "El nuevo artículo 52 c) del Estatuto de los trabajadores: primeras interpretaciones”, Aranzadi Social, Tomo-I, 1996, pág. 2611 y 2612.

${ }^{19}$ PÉREZ DE LOS COBOS ORIHUEL, F. y ROQUETA BUJ, R.: "Las llamadas <<causas económicas, técnicas, organizativas o productivas>>", Documentación Laboral, no 51, 1997, pág. 43. 
a (...) garantizar la viabilidad futura de la (...) (empresa) y del empleo en ella, a través de una más adecuada organización de los recursos". Un sector mayoritario de la doctrina judicial interpretó dicha referencia exigiendo una viabilidad comprometida como punto de partida para poder despedir ${ }^{20}$, sin que los pronunciamientos del TS, interpretando el alcance de la reforma de 1994, comportasen una lectura resueltamente censora de tal entendimiento ${ }^{21}$.

Al hilo de lo anterior, y pese a las diversas reformas habidas posteriormente, adviértase como los razonamientos de la SJS de Las Palmas que se viene reseńando guardan un alto de grado de coincidencia con alguna doctrina judicial que resulta ilustrativa de la aplicación que se vino haciendo de la reforma de 1994, según la cual "resulta indudable desde una perspectiva atinente tan sólo a la competitividad y al beneficio empresarial que cualquier proceso de automatización, robotización o, en fin, racionalización de los medios de producción contribuye genérica y abstractamente a la viabilidad de la empresa, puesto que cualquier medida cuyo designio sea un mayor beneficio empresarial comporta, por definición, una mayor viabilidad (...). De ahi que, si los Tribunales ponderaran tan sólo el factor optimización de los recursos, inatacable resultaria la lógica empresarial y, siguiendo la misma, procedentes de los despidos. Pero no existen términos hábiles para suponer que el legislador quiso desvincular tal proceso de optimización de un factor de viabilidad más concreto, limitado y tangible alcance"22.

No demasiado tiempo después, con la reforma de 1997, se introdujeron otras modificaciones que afectaron a los despidos no estrictamente económicos ex art. 52 c) ET, de nuevo con el pretendido objetivo de flexibilizar la interpretación que se venía haciendo de los mismos ${ }^{23}$. No obstante, el legislador insistió en la técnica normativa de vincular los despidos a un elemento finalista, de modo que los despidos debían contribuir "a superar las dificultades que impidan el buen funcionamiento de la empresa, ya sea por su posición competitiva en el mercado o por exigencias de la demanda, a través de una mejor organización de los recursos". Es cierto que el nuevo elemento teleológico, dada su alusión a la competitividad y a la mejora de la organización empresarial, comportó una jurisprudencia que subrayó la necesidad de suavizar las exigencias, no requiriéndose la acreditación de una situación de tal entidad como para comprometer la viabilidad empresarial; pero no es menos cierto que, sobre la base de las "dificultades" referidas en tal elemento finalista, se siguieron exigiendo problemas de funcionamiento o eficiencia empresarial reflejados, por ejemplo, en resultados negativos en las cuentas, en escasa productividad, retraso tecnológico respecto a los competidores, pérdida de cuota de mercado, etc. ${ }^{24}$. De un grupo de pronunciamientos del TS se desprendía, en efecto, que tanto los cambios técnicos-organizativos introducidos, como los despidos consecuencia de tales cambios, debían responder a problemas de gestión o eficiencia actuales, perceptibles y acreditados ${ }^{25}$. Tras este entendimiento jurisprudencial latía, a la postre, la idea de que decisiones como la implantación de procesos de automatización o la externalización de actividades, en tanto que provenientes de la voluntad exclusiva del empresario, no podían admitirse, sin más, como situación de desajuste justificativa de la amortización de puestos de trabajo ${ }^{26}$.

${ }^{20}$ Cfr. DESDENTADO BONETE, A.: “El despido...”, cit. pág. 461. Véase, por ejemplo, STSJ Galicia 8-2-1995 (Ro 63/1995); STSJ País Vasco 21-7-1995 (Ro 1107/1995); STSJ Cataluña 17-11-1995 (St. 6261/1995) y STSJ Andalucía 18-10-1996 (Ro 708/1996).

${ }^{21}$ La doctrina jurisprudencial no pasó a este respecto de algunas consideraciones en obiter dicta de las que se colegía, además, una concepción defensiva de estos despidos, como mecanismo para hacer frente a dificultades de rentabilidad o eficiencia empresarial. Cfr. STS 14-6-1996 (Ro 3099/1995) y 21-3-1997 (Ro 3755/1996).

${ }^{22}$ STSJ Cataluña 21-2-1997 (St. 1515/1997). En la misma línea, STSJ Cataluña 2-9-1997 (St. 5631/1997).

${ }^{23}$ Cfr. ALBIOL MONTESIONES, I.: "La extinción del contrato por causas objetivas", en (AAVV): La reforma laboral de 1997, Valencia, Tirant lo Blanch, 1997, pág. 71; DURÁN LÓPEZ, F. “El despido...”, cit., pág. 1109.

${ }^{24}$ Cfr., por todas, STS 10-5-2006 (Ro 725/2005).

${ }^{25}$ Cfr., entre otras, SSTS 30-3-2010 (Ro 1068/2009) y 1-7-2010 (Ro 3439/2009).

${ }^{26}$ En este sentido, valorando negativamente esta orientación jurisprudencial, RODRÍGUEZ-PIÑERO BRAVO-FERRER, M.: “Control judicial y despido”, Relaciones Laborales, no 10, 2010, pág. 9. 
Como se puede comprobar, la SJS de la Las Palmas comentada es fiel heredera de estas tesis, pues, a pesar de no haber referencia alguna en la vigente normativa, sigue exigiendo a la empresa el "deber de acreditar que real y efectivamente atraviesa por dificultades de cierta entidad" y, asimismo, asume la idea apuntada de que el excedente de mano de obra resultante de la decisión empresarial de introducir innovaciones técnico-organizativas no puede justificar el despido, pues "ha sido la propia empresa, que no tenía problemas previos, la que ha introducido un elemento que ha creado dicho desajuste (...) al adjudicar a un 'bot' el trabajo que antes desempeñaban humanos". En definitiva, la sentencia da continuidad a aquella orientación judicial que durante bastantes años ha venido entendiendo que un despido por causas técnico-organizativas sólo podía calificarse de procedente si quedaban acreditadas circunstancias con ciertos perfiles patológicos, tales como unas notables y acumuladas pérdidas económicas, una continuada pérdida de cuota de mercado o una manifiesta obsolescencia o ineficacia de la maquinaria, equipos o sistemas reemplazados ${ }^{27}$. Sin la concurrencia de este tipo de circunstancias, se entendía que el despido derivado, por ejemplo, de la instalación de un sistema automatizado de atención al cliente, que dejaba vacío de contenido un puesto de telefonista, o el despido derivado de la incorporación de unas " $P D A$ '” a la actividad de la empresa, que reducía muy considerablemente la carga de trabajo de la trabajadora despedida, no respondían una "necesidad", sino a una estrategia de mera "conveniencia" empresarial dirigida al incremento de beneficios ${ }^{28}$. Este criterio valorativo también aparece, como se ha visto, reflejado en la más reciente sentencia del JS de Las Palmas y, a mi juicio, plantea una dicotomía bastante maniquea y poco fundamentada, pues que no exista una apremiante "necesidad" de despedir para superar problemas de rentabilidad o gestión empresarial no significa que, en el marco de un sistema de libertad de empresa (art. $38 \mathrm{CE}$ ), no sea legítima la "conveniencia" empresarial de introducir, en cualquier momento, innovaciones tecnológicas y mejorar la organización de sus recursos suprimiendo un puesto de trabajo "redundante"29. Amén de que la sentencia comentada, en algún punto de su argumentación, parece querer fundamentar este tipo de valoración dicotómica en el llamado "juicio de razonabilidad"; juicio que el contexto de estos despidos no deja de ser una figura bastante borrosa, sin que, además, la más reciente doctrina judicial y jurisprudencia parezca atribuirle el sentido que la sentencia pretende otorgarle (véase infra 3.2).

Todo lo anterior lleva a reafirmarnos en la crítica a la SJS de Las Palmas comentada, toda vez que la misma aboga por una interpretación que se aparta de lo que es una lectura ajustada a la vigente letra y espíritu de la ley. En punto a las causas técnicas, el actual marco normativo, producto de la reforma de 2012, mantiene la referencia -introducida por la precedente reforma de 2010- a "cambios, entre otros, en el ámbito de los medios o instrumentos de producción". Tal identificación de las causas con "cambios" bien puede interpretarse como el reconocimiento legal de que resulta indistinto que en el origen último de los mismos radique en factores más o menos exógenos o endógenos a la voluntad empresarial, pudiendo obedecer las causas técnicas a decisiones de pura iniciativa o gestión empresarial; esto es, tomadas dentro del círculo de autonomía del empresario, quien, por razones de estrategia competitiva, planificación o similares, "crea circunstancias que pueden motivar el despido"30. Ello, unido a que, con la reforma de 2012, ha desaparecido todo elemento finalista de estos despidos,

${ }^{27}$ Cfr., entre otras, STSJ Islas Canarias 22-5-2002 (Ro 923/2001); STSJ Castilla-La Mancha 5-11-2003 (Ro 1733/2003); STSJ Islas Canarias 27-2-2009 (Ro 973/2006); STSJ Madrid 17-4-2009 (Ro 667/2009); STSJ Galicia 5-10-2010 (Ro 2424/2010).

${ }^{28}$ STSJ La Rioja 1-3-2005 (Ro 39/2005) y STSJ País Vasco 30-5-2006 (Ro 998/2006). En la misma línea, entre otras, STSJ Comunidad Valenciana (Ro 3588/2002); STSJ Cataluña 10-2-2003 (Ro 7784/2002) y 9-2-2005 (Ro 8361/2004); STSJ Islas Canarias 20-9-2004 (Ro 635/2004); STSJ Castilla y León 23-3-2005 (Ro 426/2005); STSJ Navarra 9-6-2006 (Ro 25/2006).

${ }^{29}$ En este sentido, RODRÍGUEZ-PIÑERO BRAVO-FERRER, M.: "Control...”, cit., pág. 8.

${ }^{30} \mathrm{Cfr}$., destacando la referencia legal a "cambios" que implicaría una caracterización de las causas técnico-organizativas en el sentido apuntado, GARCÍA MURCIA, J.: "Las causas...”., cit., págs. 5-7 En la misma línea, MARTÍN VALVERDE, A.: "Razonabilidad o proporcionalidad en el control judicial de la justificación del despido colectivo", en (GODINO REYES, M. Coord.): Tratado de despido colectivo, Valencia, Tirant lo Blanch, 2016, pág. 5 de la versión on-line. 
que con un tono u otro pudiera condicionarlos a una situación de inviabilidad o necesitada de mejora, constituyen argumentos de peso para sostener que con el marco normativo vigente se ha querido dar por superada aquella orientación jurisprudencial según la cual los cambios técnico-organizativos introducidos por el empresario no justificarían por sí mismos extinciones de contratos de trabajo si no van dirigidos a solventar preexistentes problemas de rentabilidad o eficiencia empresarial.

Con la supresión, en efecto, de la valoración finalista de estos despidos, el legislador ha perseguido desvincular más claramente las causas de tipo técnico y organizativo de otras razones más relacionadas con el riesgo de una evolución negativa de la empresa, así como superar la indefinición inherente a tales elementos finalistas. El legislador optó, en este sentido, por evitar una semántica que recordase a normas precedentes, intentando así sortear una inercia aplicativa en que la ambigüedad legal sirviese de pretexto para una fiscalización judicial que alcanzase a aspectos que tras la reforma se juzgan como claramente correspondientes a la esfera de la libre decisión empresarial. Que los propósitos del legislador de 2012 se mueven en esta dirección se deduce con nitidez de algunos pasajes de las exposiciones de motivos del RD-Ley 3/2012 y de la Ley 3/2012, en los que se puede leer una crítica al modelo anterior, entre otras razones, por haber "venido caracterizándose por una ambivalente doctrina judicial y jurisprudencia, en la que ha primado muchas veces una concepción meramente defensiva de estos despidos, como mecanismo para hacer frente a graves problemas económicos, soslayando otras funciones que está destinado a cumplir este despido como cauce para ajustar el volumen de empleo a los cambios técnico-organizativos operados en las empresas"; y este es uno de los motivos por los cuales la "ley se ciñe ahora a delimitar las causas (...) que justifican estos despidos, suprimiéndose otras referencias normativas que han venido introduciendo elementos de incertidumbre. Más allá del concreto tenor legal incorporado por diversas reformas desde la Ley 11/1994 (...) tales referencias incorporaban proyecciones de futuro, de imposible prueba, y una valoración finalista de estos despidos, que ha venido dando lugar a que los tribunales realizasen, en numerosas ocasiones, juicios de oportunidad relativos a la gestión de la empresa. Ahora queda claro que el control judicial de estos despidos debe ceñirse a una valoración sobre la concurrencia de unos hechos: las causas".

Por consiguiente, en el actual marco normativo, cuando se trata de justificar despidos vinculados a la introducción de cambios tecnológicos en la empresa, no cabe exigir que tales cambios obedezcan a problemas o dificultades ya constatadas, ni tampoco acreditar nada acerca de la repercusión más o menos positiva de dichos cambios en la viabilidad o evolución de la empresa. Tras la reforma operada en 2012, se puede, en efecto, afirmar de un modo concluyente la autonomía e independencia de las causas técnicas y organizativas respecto a otras razones que se incardinan en mayor medida en la noción de causas económicas o productivas, admitiéndose, por tanto, el despido por la introducción de cambios tecnológicos en una empresa con beneficios económicos y sin signos de una evolución negativa o deterioro alguno ${ }^{31}$. Y, ciertamente, en la doctrina judicial posterior a la reforma se constata una orientación judicial mayoritaria tendente a declarar la procedencia del despido sin necesidad de que el cambio tecnológico acreditado responda a otras circunstancias tales como pérdidas, una reducción de la cuota mercado, ni tampoco a una obsolescencia de los medios de producción renovados o cualquier otra ineficiencia productiva ${ }^{32}$.

Con todo, también es cierto que puntualmente sigue detectándose alguna doctrina judicial que, en la misma línea de la SJS de Las Palmas reseñada, juzga improcedente la decisión extintiva

\footnotetext{
${ }^{31}$ Cfr. CRUZ VILLALÓN, J.: "Las transformaciones...", cit., pág. 35.

${ }^{32}$ Cfr., entre otras, STSJ Galicia 27-1-2015 (Ro 3505/2014); STSJ Cataluña 9-6-2016 (Ro 2167/2016); STSJ Andalucía 226-2017 (Ro 2534/2016); STSJ Comunidad Valenciana 23-10-2018 (Ro 2587/2018). La circunstancia relativa a la obsolescencia de los medios de producción aparece reflejada en la STS 22-2-2018 ( $\mathrm{R}^{\circ}$ 192/2017), en que se declara ajustado a derecho un despido colectivo por causas técnicas y organizativas, pero no parece que el Alto Tribunal subraye ello como un elemento estrictamente necesario para la justificación de estos despidos, sino que tal referencia aparece de manera más bien circunstancial como algo propio del supuesto de hecho concreto.
} 
por la falta de prueba de circunstancias que pongan manifiesto que los cambios tecnológicos introducidos y el despido acordado no responden a una mera "conveniencia" empresarial ${ }^{33}$. Habrá quien pueda considerar que ello es imputable a la parquedad de la norma vigente, que, al referirse sin más a las causas, redunda también en indefinición, pero de algunos de los razonamientos esgrimidos por la SJS comentada y alguna otra sentencia se deduce una suerte de resistencia a aceptar que la ley ha cambiado y que -guste o no- de la actual regulación del despido por causas económicas, técnicas, organizativas o de producción, así como de otras instituciones relacionadas sobre todo con la flexibilidad interna, se colige una más nítida y mayor apuesta del legislador por la competitividad de las empresas como garantía del mantenimiento y la creación del empleo, no sólo a corto, sino también a medio y largo plazo. Frente a ello, la sentencia reseńada plantea una disyuntiva excesivamente excluyente entre la libertad de empresa y la competitividad empresarial, de un lado, y el derecho al trabajo y el mantenimiento del empleo, por otro lado; y lo hace, en el caso concreto, bajo la justificación de que la robotización y automatización pueden destruir un notable volumen de empleo, lo que, según su entendimiento, exige una "reinterpretación" de la causa técnica que la circunscriba a las empresas con dificultades, no considerándose de recibo que todos aquellos trabajadores que pudieran ser despedidos por tal efecto de la automatización perciban "una indemnización inferior a la ordinaria"; idea ésta sobre la indemnización que debe ser considerada la ordinara que, como se vio, es reiterada en varias puntos por la sentencia, pero que, sin embargo, parece muy forzado deducir de la normativa vigente. Sea como fuere, se comparta o no dicha visión sobre los efectos de la automatización en el mercado de trabajo y se comparta o no el escaso valor que se le otorga a que las empresas puedan mejorar su competitividad, lo que, a mi juicio, parece claro es que este tipo de razonamientos judiciales se inmiscuye en el terreno de valoraciones y decisiones propias del legislador.

\section{Sobre el control judicial de los despidos por causas técnicas}

\subsection{La acreditación del cambio técnico y de su relación causa-efecto con el despido}

No parece que haya duda de que el ordenamiento vigente reconoce que compete al empresario valorar y decidir la implantación de modificaciones técnico-organizativas en su estructura productiva, lo que no quiere decir que la ley no intervenga fijando límites respecto a los efectos que se pueden producir sobre los contratos de trabajo. En este sentido, en contra de la opinión que se ha difundido, de forma algo grandilocuente, acerca de que tras la reforma laboral de 2012 se ha reducido prácticamente a nada o aspectos meramente formales la fiscalización judicial de estos despidos ${ }^{34}$, lo cierto es que resulta plenamente vigente un control sustancial que, centrando la atención en el despido asociado a la introducción de innovaciones tecnológicas en la empresa, giraría en torno a los siguientes elementos:

En primer lugar, sobre el empresario recae la carga de probar el cambio tecnológico o, en la terminología legal, la existencia de "cambios" en los "medios o instrumentos de producción" -causas técnicas-, sin perjuicio de que pueda ser frecuente que ello conlleve también cambios en los "sistemas y métodos de trabajo del o en el modo de organizar personal" -causas organizativas- (art. 51.1.

${ }_{33}^{3}$ STSJ La Rioja 26-9-2016 (Ro 176/2016). En la misma línea, STSJ Islas Canarias 27-11-2015 (Ro 835/2015), que expresa una clara toma de posición respecto a que el control judicial, pese a los cambios legales introducidos, debe seguir pivotando sobre un elemento finalista vinculado a problemas de eficiencia o rentabilidad empresarial, por lo que, en el caso concreto, se admite el despido fundado en la automatización de un servicio de atención telefónica sólo en la medida que el mismo se considera adecuado frente al notable descenso de ventas empresariales acreditado.

${ }^{34}$ Representativo en este sentido es el trabajo del Magistrado de lo Social FALGUERA BARÓ, M. A.: La causalidady su prueba en los despidos económicos, técnicos, organizativos y productivos tras la reforma laboral, Bomarzo, Albacete, 2013, en particular pág. 47 y ss. 
ET), y sin perjuicio de que, además, puedan -aunque no es necesario- concurrir otras causas de orden económico o productivo (pérdidas, disminución de ingresos, reducción de la demanda, etc.). Es obvio que la reforma laboral de 2012 ha mantenido intacto el control judicial sobre la realidad y actualidad de la causa. Por ello, ni antes ni ahora, resulta procedente el despido acometido sobre la base de meros proyectos y con anterioridad a la efectiva implantación del cambio ${ }^{35}$. Una vez acreditado el cambio, aunque la ley no atribuye al juez la labor de controlar las razones a las que obedece, sí que le permite valorar los efectos que del mismo se derivan para las relaciones laborales. Ello constituye el segundo elemento del control judicial en estos casos.

En segundo lugar, en efecto, para que el cambio tecnológico justifique la extinción de contratos de trabajo, debe tener una repercusión directa sobre el ámbito en el que el trabajador despedido presta sus servicios. De este modo, como cierta doctrina subrayó hace tiempo, pieza central de la apreciación de legitimidad de este tipo de despidos lo constituye el hecho de que la causa haya comportado un concreto excedente de personal, permitiendo que el empresario haga frente al sobredimensionamiento de la plantilla ${ }^{36}$. De suerte tal que es más la crisis del contrato, que no la crisis de la empresa, lo que se pone de manifiesto en tales casos y, en consecuencia, la decisión extintiva se justificará en la medida que responda proporcionadamente al desequilibrio de prestaciones entre empleado y empleador, consideraciones al margen sobre la situación global de la empresa ${ }^{37}$. Es cierto que el actual tipo normativo, ceñido a describir las causas, no alude a este segundo momento del control judicial, como tampoco lo hacían de modo explícito sus precedentes normativos, si bien, a este respecto, podía resultar indicativa la dicción que vino encabezando al art. 52 c) ET durante tiempo, refiriéndose a "la necesidad objetivamente acreditada de amortizar puestos de trabajo" y que fue suprimida, a partir de la reforma de 2010, probablemente con el propósito de dejar atrás la discutible dicotomía, antes apuntada, entre "necesidad" y "conveniencia" presente en la valoración judicial de estos despidos ${ }^{38}$. Una lectura más cabal de la citada dicción debería haber llevado a considerar que ello no era otra cosa que una referencia a la necesaria afectación de la causa probada sobre un concreto o concretos puestos de trabajo como requisito para justificar el despido. Que la citada referencia legal haya desparecido desde la reforma 2010 no significa que una fiscalización en tal sentido no siga siendo procedente y operativa ${ }^{39}$, tal y como así se desprende de la doctrina de suplicación más reciente relativa a los despidos por causas técnicas ${ }^{40}$.

Además, la pertinencia de este tipo de control constituye, a mi juicio, una consecuencia lógica del sometimiento de los poderes empresariales a los principios generales de buena fe y de prohibición de abuso del derecho (art. 7 CC) ${ }^{41}$. Estos principios remiten a un ejercicio de todo

\footnotetext{
${ }^{35}$ Cfr. STSJ Extremadura 18-4-2000 (Ro 205/2000); STSJ Madrid 7-3-2014 (Ro 1950/2013); STSJ Andalucía 20-11-2015 (Ro 2842/2014).

${ }^{36}$ MONTOYA MELGAR, A.: “El nuevo...”, cit., pág. 2612.

${ }^{37}$ En este sentido, DESDENTADO BONETE, A.: “El despido...”, cit. pág. 467.

${ }^{38}$ Así interpretó la citada supresión DESDENTADO BONETE, A.: "La reforma...", cit., pág. 90.

${ }^{39}$ Cfr. DESDENTADO BONETE, A.: "La reforma...”, cit., pág. 90; GOERLICH PESET, J. M.: "La reforma de la extinción del contrato de trabajo", Temas Laborales, no 107, 2010, pág. 280.

${ }^{40}$ Cfr., entre otras, STSJ Galicia19-7-2016 (Ro 921/2016); STSJ Andalucía 17-5-2016 (Ro 1385/2015); STSJ Cataluña 9-62016 (Ro 2167/2016); STSJ Cantabria 31-10-2018 (Ro 590/2018); STSJ Madrid 7-2-2019 (Ro 933/2018); STSJ Andalucía 14-22019 (Ro 2006/2018); STSJ Madrid 7-10-2019 (Ro 775/2019).

${ }^{41}$ Cfr., señalando que el hecho de que la actual regulación de los despidos ex art. 51 y 52 c) ET se limite a exigir la acreditación de la causa no obsta para que las decisiones extintivas queden sujetas a tales principios, GOERLICH PESET, J. M.: "La extinción del contrato de trabajo en el Real Decreto-Ley 3/2012", en GARCIA-PERROTE ESCARTÍN, I. y MERCADER UGUINA, J. (Dirs.): Análisis práctico del RDL 3/2012, de medidas urgentes para la reforma del mercado laboral, Valladolid, Lex Nova, 2012, pág. 303; BLASCO PELLICER, A.: "La extinción del contrato de trabajo en el RDL 3/2012. Aspectos sustantivos, procesales y de Seguridad Social”, en (AAVV): La reforma laboral en el Real Decreto-Ley 3/2012, Valencia, Tirant lo Blanch, 2012, pág. 166; GARCÍAPERROTE ESCARTÍN, I.: "La nueva regulación sustantiva y procesal de la extinción del contrato de trabajo en el Real Decreto-Ley 3/2012”, Actualidad Laboral, no 9, 2012, pág. 2 de la versión de internet.
} 
poder o derecho no contrario a su función económica-social ${ }^{42}$, que, en este caso, atendiendo a la ratio legis vigente, no es otra que acomodar el volumen de empleo en la empresa al concreto cambio de circunstancias acreditado. Como apunta alguna doctrina judicial, se trata de una valoración que se deriva de la propia naturaleza de las causas técnico-organizativas, las cuales, como se desprende de su descripción normativa, deben tener un ámbito de afectación concreto -unos determinados medios, instrumentos, sistemas o métodos de producción-y es en relación a tales ámbitos que pueden justificar la extinción del contrato de trabajo ${ }^{43}$. Se trata, por tanto, de valorar si el despido es razonable, pero no desde la perspectiva de diversas posibles ponderaciones concernientes a la evolución y gestión empresarial -no presentes ya en el tipo normativo en cuestión-, sino si resulta razonable para adecuar el volumen de empleo de la empresa a la situación resultante del cambio técnico-organizativo acreditado. Se trata, en suma, de un control sobre los límites “internos" del poder extintivo del empresario ${ }^{44}$.

Como se avanzó al comentar la SJS de Las Palmas de 23-9-2019 (véase supra 2), en este segundo momento la labor judicial consiste en ponderar si la supresión del puesto de trabajo del trabajador o trabajadores despedidos guarda una relación causa-efecto con el cambio técnico acreditado, de modo que únicamente será legítimo el despido del trabajador de cuyas tareas y responsabilidades se pueda prescindir como consecuencia de dicho cambio. Y, como también se apuntó al reseñar la citada SJS, ello conlleva un control que, aunque circunscrito a unos hechos y pruebas muy específicas, no por ello deja de ser muy trascendente desde el punto de vista de las facultades de fiscalización judicial en esta materia. Cabe exigir, en efecto, que se aporten datos acerca de las concretas tareas que venían ocupando al trabajador o trabajadores despedidos y de cómo ha incidido en ellas el cambio técnico; exigencia que, por ejemplo, lleva a afirmar que no basta con probar que, en una sección de la empresa, se han sustituido 3 máquinas por 2 más productivas para justificar, sin mayores datos, el despido de 9 trabajadores de dicha sección ${ }^{45}$; o exigencia que lleva a concluir que el puesto de la trabajadora despedida no se había visto afectado de modo sustancial por el cambio tecnológico, toda vez que el mismo se había introducido en el área de cajas y las funciones de las trabajadora eran de gestión y coordinación general del establecimiento ${ }^{46}$. Asimismo, en este terreno, también puede adquirir relevancia la conexión temporal entre la implantación del cambio y la decisión extintiva, pues el hecho de que transcurra un lapso de tiempo relevante entre ambas circunstancias puede denotar que el cambio no implicaba la necesidad de amortizar el puesto ${ }^{47}$. Nótese, en todo caso, que, según un reiterado criterio jurisprudencial, la noción de "amortización" iría referida a los puestos de trabajo afectados por la reestructuración empresarial y no a las funciones desarrolladas por los trabajadores en ellos ocupados, pues las mismas pueden seguir formando parte del conjunto de la actividad empresarial ${ }^{48}$. La causa acreditada debe implicar un excedente en el nivel de empleo en la empresa, pero no necesariamente una desaparición de las funciones que venía realizando el trabajador despedido, que pueden seguir siendo necesarias y ejecutadas por el propio empresario, por otros trabajadores o por un tercero a través de una contrata de obras o servicios ${ }^{49}$; a

\footnotetext{
${ }^{42}$ Cfr. MARTÍN BERNAL, J. M.: El abuso del Derecho, Madrid, Montecorvo, 1982, pág. 258 y ss.

${ }^{43}$ Cfr., fundamentando el alcance del control judicial en instituciones de aplicación general como el abuso de derecho, STSJ Madrid 18-7-2016 (Ro 168/2016).

${ }^{44}$ Sobre la distinción entre límites "externos" e "internos" a los poderes empresariales, vinculados los segundos a un ejercicio de buena fe y no abusivo ex art. art. 7 CC, MONTOYA MELGAR, A.: La buena fe en el Derecho del Trabajo, Madrid, Tecnos, 2001, pág. 79 y 80.

${ }^{45}$ STSJ Madrid 7-10-2019 (Ro 775/2019).

${ }^{46}$ STSJ Andalucía 14-11-2019 (Ro 939/2019).

${ }^{47}$ Cfr. STSJ País Vasco 12-4-2011 (Ro 423/2011); STSJ Galicia 19-7-2016 (Ro 921/2016); STSJ Madrid 13-7-2017 (Ro 398/2017); STSJ Cantabria 31-10-2018 (Ro 590/2018).

${ }^{48}$ Cfr. SSTS 14-6-1996 (Ro 3099/1995); 29-5-2001 (Ro 2022/2000); 15-10-2003 (Ro 1205/2003); 12-6-2012 (Ro 3638/2011).

${ }^{49}$ En este sentido, GOERLICH PESET, J. M.: “La reforma...”, cit., pág. 280.
} 
lo que cabría añadir, asimismo, la posibilidad de que las mismas hayan quedado fundamentalmente automatizadas a raíz del cambio tecnológico introducido.

La valoración judicial en torno a si concurre la relación causa-efecto entre el cambio técnico y el puesto del trabajador despedido, haciéndolo suprimible, es una ponderación, como se decía, de aspectos fácticos, sin que proceda traer a colación otros argumentos relativos a las normas de calidad, seguridad, accesibilidad, etc. exigidas a los servicios prestados por la empresa. Con ello me estoy refiriendo particularmente a las normas aprobadas por un buen número de CCAA, que han limitado o prohibido las gasolineras completamente automatizadas ${ }^{50}$. Sin que quepa entrar aquí en las diversas cuestiones que estas normativas plantean desde el punto de vista de la distribución de competencias entre Estado y CCAA ${ }^{51}$, desde el estricto prisma jurídico-laboral no resulta de recibo que tales normativas autonómicas interfieran en la aplicación de lo previsto en los arts. 51 y 52 c) ET. Y, por ello, no resulta posible declarar la improcedencia de un despido arguyendo que, a pesar de la automatización implantada, los servicios laborales siguen siendo necesarios para cumplir con una normativa como la aprobada, por ejemplo, por la Junta de Andalucía, que exige la presencia obligatoria de "una persona para atender la solicitud de suministro de combustible (...)" (art. 7.7 Decreto 537/2004). Este tipo de previsiones podrán desplegar, en su caso, los efectos jurídicos que correspondan desde el punto de vista de las competencias autonómicas, pero no pueden derogar de facto los poderes empresariales de extinción del contrato de trabajo recogidos en un legislación competencia exclusiva del Estado (art. 149.1.7 CE); amén de que en el caso particular la norma autonómica no exige que el personal que debe estar presente sea un trabajador por cuenta ajena contratado directamente por la empresa, pudiendo la misma recurrir a distintas fórmulas para intentar cumplir con la exigencia autonómica ${ }^{52}$.

Al hilo de todo lo anterior, si lo relevante es que el cambio técnico haya comportado la necesidad de amortizar el puesto de trabajo del trabajador despedido, una circunstancia adicional a valorar serán las nuevas contrataciones que haya podido efectuar la empresa de un modo más o menos coetáneo, pues ello puede poner de relieve que, en realidad, no ha tenido lugar dicha amortización ${ }^{53}$. Ciertamente, como se desprende de la doctrina judicial, las eventuales contrataciones que la empresa formalice en un tiempo próximamente anterior o posterior a la decisión de despedir pueden comportar la calificación de improcedencia del despido cuando las mismas pongan de manifiesto que los cambios técnico-organizativos no han provocado una efectiva y relevante reducción de las tareas a despeñar por el trabajador despedido; esto es, nuevas contrataciones para desarrollar tareas que hubieran ocupado en circunstancias normales y de modo fundamental al trabajador despedido $^{54}$. Y es que como se desprende de una reciente STS -relativa a un despido aduciendo causas productivas, pero resultando extrapolable su razonamiento a los efectos que aquí interesan-, no

${ }^{50}$ Según un estudio de la Comisión Nacional de los Mercados y la Competencia, al menos, 14 CCAA habrían aprobado normativas en este sentido. Cfr. Análisis del efecto competitivo de la entrada de gasolineras automáticas en el mercado de distribución minorista de carburantes, Madrid, 2019, pág. 21.

${ }^{51}$ La STS (Cont.-Admvo) 12-2-2019 (Ro 1718/2018) confirmó una sentencia del TSJ de Baleares que declaró nula las previsiones de la respectiva normativa autonómica que prohibía las estaciones de servicios desatendidas por entender que dicha normativa invadía las competencias estatales en materia de planificación de la actividad económica y régimen energético correspondientes a la legislación que prevé la posibilidad de este tipo de estaciones.

52 En esta línea, revocando las sentencias de instancia que habían declarado la improcedencia de los despidos, SSTJ Andalucía $17-9-2015$ (Ro 1535/2015) y 18-2-2016 (Ro 2945/2015).

${ }^{53}$ En este sentido, respecto al noción de despido por "necesidad de amortización" se ha venido señalando que el mismo requiere para justificarse que no vaya acompañado de una nueva contratación para sustituir al despedido. Cfr. RODRÍGUEZ-PINEERO BRAVO-FERRER, M.: "El despido por motivos objetivos atinentes a la empresa", Relaciones Laborales, no 1, 1998, pág. 85.

${ }^{54}$ Este tipo de valoración judicial, que comporta la improcedencia del despido, se puede observar en pronunciamientos dictados durante la vigencia de textos legales que incluían la referencia a la necesidad de "amortizar" puestos de trabajo -cfr., por ejemplo, STSJ Galicia 30-4-2001 (Ro 797/2001)-, y también en sentencias posteriores, a pesar de haber desparecido dicha referencia normativa. Cfr. STSJ Andalucía 20-11-2015 (Ro 2842/2014); STSJ Madrid 18-7-2016 (Ro 168/2016); STSJ Cantabria 31-10-2018 (Ro 590/2018). 
se puede apreciar una incidencia de la causa alegada sobre el volumen de empleo cuando paralelamente a la pretendida afectación de la causa invocada se han realizado contrataciones para el centro de trabajo y las funciones del trabajador despedido, sin que la empresa aporte una justificación sobre las necesidades coyunturales a las que podían obedecer tales contrataciones ${ }^{55}$. Ahora bien, de modo consecuente, no cabe considerar, en cambio, injustificado el despido si las contrataciones han ido dirigidas a cubrir necesidades de otras áreas funcionales o unidades productivas diferentes a aquellas en que se ha introducido el cambio tecnológico ${ }^{56}$, ni tampoco cuando las nuevas contrataciones, aunque puedan guardar relación con las funciones que venía desempeñando el despedido -que, como se decía, pueden seguir formando parte de la actividad empresarial-, respondan a necesidades coyunturales, tales como puntas de trabajo o la cobertura de trabajadores ausentes (vacaciones, incapacidad temporal, reducciones de jornada, etc. $)^{57}$. Desaparecida toda referencia legal que pudiese llevar a considerar que los despidos por motivos técnico-organizativos quedan condicionados a una situación de riesgo para la viabilidad empresarial, no procede ya dar relevancia a cualquier contratación laboral efectuada por la empresa con independencia de su finalidad ${ }^{58}$, como en ocasiones venía haciendo la doctrina judicial otorgándole el valor de dato indicativo de la inexistencia de dificultades para la continuidad y mantenimiento de la actividad empresarial y declarando, por ello, no ajustado a derecho el despido ${ }^{59}$.

Que las nuevas contrataciones efectuadas por el empresario para cubrir otras áreas funcionales o unidades productivas distintas a las afectadas por el cambio tecnológico no impidan la procedencia del despido resulta coherente con el hecho de que, por contraste con lo expresamente prescrito por textos legales anteriores a la reforma laboral de $1994^{60}$, el empresario no esté obligado a intentar la recolocación del trabajador cuyo puesto de trabajo ha resultado carente de sentido a raíz de la introducción del cambio técnico ${ }^{61}$. Como ha venido, en efecto, afirmando de forma reiterada la jurisprudencia, la ley "no impone al empresario la obligación de agotar todas las posibilidades de acomodo del trabajador en la empresa", ni obliga, por tanto, "antes de hacer efectivo el despido (...) a destinar el empleado a "otro puesto" vacante de la misma"62. Aunque, como se verá más adelante, el TS no siempre ha sido consecuente con estas aseveraciones, no hay duda sobre la clara inclinación a no condicionar la legitimidad de los despidos a una valoración sobre las alternativas de gestión laboral en manos del empresario. Y si el empresario no queda obligado a recurrir a mecanismos de movilidad, funcional y/o espacial, otro tanto cabe pensar respecto a otras posibles medidas. Así, puede ser que el cambio tecnológico haya reducido, aunque no eliminado del todo, las tareas a desarrollar por el trabajador, de modo que cabría la posibilidad que el mismo pudiera seguir prestando servicios

\footnotetext{
${ }^{55}$ STS 28-2-2018 (Ro 1731/2016).

${ }^{56}$ En esta línea, STSJ Madrid 17-2-2014 (Ro 1386/2013); STSJ Andalucía 17-5-2016 (Ro 1385/2015); STSJ Castilla-La Mancha 20-5-2019 (Ro 305/2019).

${ }^{57}$ En esta línea, STSJ Galicia 27-6-2011 (Ro 1320/2011); STSJ Murcia 5-3-2012 (Ro 951/2011); STSJ Andalucía 17-5-2016 (Ro 1385/2015); STSJ Comunidad Valenciana 4-4-2017 (Ro 99/2017).

${ }^{58}$ En esta línea, LLOMPART BENNASSAR, M.: "Poder legislativo versus poder judicial en los despidos por causas económicas, técnicas, organizativas o de producción”, Trabajo y Derecho, no 18, 2016, pág. 28.

${ }^{59}$ Cfr. SSTSJ Cataluña 2-3-1998 (St. 1752/1998) y 23-10-1998 (St. 7358/1998). En la misma línea, STSJ Madrid 16-1-1998 (Ro 4132/1997); STSJ Comunidad Valenciana 24-2-2000 (Ro 1984/1999).

${ }^{60}$ Tanto el despido individual por necesidades de funcionamiento de la empresa contemplado por el RD-Ley de Relaciones de Trabajo de 1977, como el despido individual por amortización del puesto de trabajo regulado en el Estatuto de los trabajadores de 1980, se condicionaban -sin perjuicio de los matices existentes entre ambas normativas- a que no procediese utilizar al trabajador afectado en otras tareas. Al respecto, BRIONES GONZÁLEZ, C.: La extinción del contrato de trabajo por causas objetivas, Madrid, MTAS, 1995, pág. 195 y ss.

${ }^{61}$ En esta línea, en la reciente doctrina judicial relativa a despidos por causas técnicas, STSJ Andalucía 17-5-2016 (Ro 1385/2015); STSJ Castilla-La Mancha 20-5-2019 (Ro 305/2019); STSJ Madrid 7-10-2019 (Ro 775/2019).

${ }^{62}$ Entre otras, SSTS 13-2-2002 (Ro 1496/2001), 21-7-2003 (Ro 4454/2002); 16-9-2009 (Ro 2027/2008); 31-1-2013 (Ro 709/2012) y 31-1-2018 (Ro 1990/2016).
} 
con una consecuente reducción del tiempo de trabajo. Como ha confirmado el TS, en tales casos no resulta aplicable el art. 41 ET sobre modificaciones sustanciales de las condiciones de trabajo, dado que la conversión de jornada completa a tiempo parcial supone una novación contractual que exige la voluntariedad y consentimiento del trabajador, tal y como prevé el art. 12.4 e) ET; y, por tanto, si el empresario hace tal oferta al trabajador y la misma es rechazada, quedará plenamente abierta la posibilidad de acometer una extinción contractual ex art. 52 c) ET ${ }^{63}$; pero, en todo caso, no parece que el empresario quede obligado a tal ofrecimiento, pues no hay base legal para entender que la eficacia del mecanismo extintivo quede condicionada a intentar aplicar otros mecanismos previamente ${ }^{64}$. En este sentido, la jurisprudencia más reciente también apunta a que la valoración de si caben medidas alternativas al despido constituye juicio de oportunidad que corresponde a la gestión a empresarial ${ }^{65}$.

Por lo demás, el hecho de que el trabajador despedido por razones técnicas estuviera afectado en el momento del despido por otra medida de ajuste empresarial -vgr. una reducción de jornada o suspensión contractual temporal ex art. 47 ET o una inaplicación de convenio ex art. 82.3 ET-, no afecta a la legitimidad de aquél, siempre que se acredite que la causa técnica acreditada es diversa y sobrevenida a la causa justificativa de la otra medida previamente adoptada. En este sentido, resulta posible que una empresa en fase de ajuste por causas económicas y productivas motivadoras de un procedimiento de suspensión de las relaciones laborales decida extinguir el contrato de alguno o algunos de los trabajadores afectados por tal suspensión, si acredita que se han introducido unos nuevos instrumentos y procedimientos de trabajo -causas técnicas y organizativas- que implican la automatización de las funciones de determinados puestos de trabajo y, por ende, su carácter suprimible ${ }^{66}$.

Adviértase, en fin, que con la constatación de relación causa-efecto entre la causa tecnológica acreditada y el puesto o puestos de trabajo amortizados, también se podrán despejar dudas sobre la posible arbitrariedad y discriminación del empresario en la selección del trabajador o trabajadores afectados por la decisión extintiva. Ciertamente, en la propia idiosincrasia de las causas de orden técnico-organizativo y de su control judicial va implícita una sindicación de que el despido de uno o varios trabajadores concretos no responde a motivos caprichosos, espurios o contrarios a los derechos fundamentales. Puede ocurrir, no obstante, que sean varios los contratos de trabajo afectados por la concurrencia del elemento causal y el despido vaya limitarse a alguno/s de ellos. A este respecto, a tenor de lo que viene declarando la doctrina judicial y la jurisprudencia, hay que entender que queda dentro de los poderes empresariales "precisar de cuál de los trabajadores que cumplen la misma función y ocupan uno de los puestos amortizables se puede prescindir ${ }^{267}$. En efecto, sin obviar la prioridad de permanencia en el puesto de trabajo de los representantes de los trabajadores prevista expresamente por la ley [arts. 51.5, 52 c) y 68 b) ET y 10.3 LOLS], la designación de los trabajadores afectados por el despido constituye una manifestación del poder de dirección y organización del

\footnotetext{
${ }^{63}$ STS 30-5-2018 (Ro 2329/2016).

${ }^{64}$ En este sentido, con carácter general se ha afirmado que, en cada caso concreto, el empresario puede argumentar que se han intentado otras medidas para hacer frente a la situación empresarial a la que se pretende hacer frente con el despido y que tales medidas no han sido posibles o que no se han revelado adecuadas; ello puede reforzar la posición empresarial ante el juez, pero en modo la ley obliga a una justificación en tal sentido. Véase GARCÍA-PERROTE ESCARTÍN, I.: "La nueva...", cit., pág. 1. En esta misma línea, LLOMPART BENNASSAR, M.: "Poder...”, cit., pág. 30 y 39.

${ }^{65}$ Cfr. SSTS 17-7-2014 (Ro 32/2014) y 20-7-2016 (R० 303/2014).

${ }^{66}$ En este sentido, declarando procedente el despido, STSJ Asturias 15-11-2013 (Ro 1829/2013). Esta doctrina judicial resulta congruente con la jurisprudencia que ha admitido la posibilidad extinguir contratos de trabajo durante el periodo de afectación de una suspensión temporal de empleo cuando concurra una causa distinta y sobrevenida a la invocada para la suspensión o bien, si la causa es la misma, cuando se haya producido un cambio trascendente y notorio de las circunstancias que determinaron la suspensión. Cfr., entre otras, SSTS 12-3-2014 (Ro 673/2013), 18-3-2014 (Ro 15/2013) y 17-7-2014 (Ro 32/2014).

${ }^{67}$ STSJ Cataluña 20-1-1999 (Ro 5325/1998). En esta misma línea, en la doctrina judicial reciente relativa a los despidos por causas técnicas, STSJ Galicia 18-6-2014 (Ro 924/2014); STSJ Madrid 7-2-2019 (Ro 933/2018).
} 
empresario "y su decisión sólo será revisable por los órganos judiciales cuando resulte apreciable fraude de ley o abuso de derecho o cuando la selección se realice por móviles discriminatorios ${ }^{268}$.

\subsection{Sobre el pretendido y ambiguo control de razonabilidad y proporcionalidad del despido}

Hasta aquí los principales elementos y cuestiones a considerar en la justificación y control judicial de los despidos por causas técnicas. Una vez abandonada, con la reforma de 2012, la caracterización teleológica de estos despidos, ya no procede tomar en consideración un tercer elemento del control judicial tradicionalmente referido en la jurisprudencia y doctrina judicial mediante la llamada " $c o-$ nexión de funcionalidad"; esto es, la valoración de los despidos desde el punto de vista de su conexión con unos fines prefijados normativamente ${ }^{69}$. Esta suerte de "confusión causas-fines" iniciada con la reforma laboral de 1994 se mantuvo todavía presente con la reforma de 2010, que aludía a "la razonabilidad de la decisión extintiva para contribuir a prevenir una evolución negativa de la empresa o a mejorar la situación de la misma a través de una más adecuada organización de los recursos, que favorezca su posición competitiva en el mercado o una mejor respuesta a las exigencias de la demanda". No han faltado voces críticas, sobre todo desde la judicatura, con el hecho de que la supresión de la valoración finalista de los despidos haya comportado también la eliminación de la referencia al carácter razonable de los mismos ${ }^{71}$. Sin embargo, una visión amplia de las distintas posturas existentes en torno al juicio de razonabilidad en el contexto de estos despidos permite afirmar que el legislador no ha querido evitar todo juicio de razonabilidad -así se deduce si, como en el esquema hermenéutico antes esbozado, la razonabilidad se pone en relación con los límites "internos" del poder extintivo; esto es, con la propia causa acreditada-, sino que lo que se ha pretendido es evitar interpretaciones ancladas en las orientaciones de textos legales anteriores -como, en buena medida, ocurre en la SJS de Las Palmas antes reseńada ${ }^{72}$, así como reaccionar frente a otras posibles concepciones de dicho juicio razonabilidad, que podrían llegar a introducir niveles de incertidumbre y rigidez -trasladando márgenes de discrecionalidad empresarial a los órganos judiciales- incluso superiores a los que se desprendían de las interpretaciones mayoritarias anteriores a la reforma de 2012. Y es que el significado y alcance atribuido al juicio de razonabilidad no ha venido caracterizándose, en la materia que nos ocupa, por su claridad y uniformidad ${ }^{73}$.

En este sentido, no deja de ser curioso que para un relevante sector doctrinal el juicio de razonabilidad, especialmente subrayado por la reforma de 2010, debía interpretarse como un freno a la intensidad y extensión del control judicial. Que la "conexión de funcionalidad" de los despidos fuese acompañada de la alusión a un juicio de razonabilidad se valoraba, en efecto, como un mensaje a

\footnotetext{
${ }^{68}$ STS 19-9-1998 (Ro 1460/1997). En el mismo sentido, STSS 15-10-2003 (Ro 1205/2003) y 24-11-2015 (Ro 1681/2014).

${ }^{69}$ En este sentido, señalando que resulta clara y patente la voluntad del legislador de omitir y no exigir un juicio vinculado a tal "conexión de funcionalidad", STSJ Madrid 18-7-2016 (Ro 168/2016).

${ }^{70}$ PÉREZ DE LOS COBOS ORIHUEL. F. y ROQUETA BUJ, R.: “Las llamadas...”, cit., pág. 42.

${ }^{71}$ Cfr. AGUSTÍ MARAGALL, J. y SERNA CALVO, M.: "Impugnación judicial de los despidos colectivos en el RDL 3/2012: ¿cuál debe ser el alcance del control judicial de la causa?”, Aranzadi Social, no 1, 2012, pág. 4 y ss. de la versión de internet; GONZÁLEZ GONZÁLEZ, C.: "Control judicial del despido colectivo tras el Real Decreto-Ley 3/2012, de 10 de febrero", Aranzadi Doctrinal, no 2, 2012, pág. 6 y ss. de la versión de internet; FALGUERA BARÓ, M. A.: La causalidad..., cit., pág. 53 y ss.

${ }^{72}$ Pese al silencio de la norma vigente y sin demasiadas argumentaciones, dicha SJS considera que el juicio de razonabilidad exige que la procedencia de los despidos derivados de la automatización de funciones se condicione a que la empresa atraviese dificultades de cierta entidad, pues, según la sentencia, la "razonabilidad de la medida no puede encontrarse en la mera conveniencia económica de introducir un "instrumento" (...) frente a una "persona"”.

${ }^{73}$ En este sentido, desde las primeras valoraciones de la reforma de 1994 ya se pusieron de manifiesto las preocupaciones acerca de la diversidad de criterios judiciales sobre el alcance del control de razonabilidad en los despidos objetivos. Cfr. DESDENTADO BONETE, A.: "El despido...", cit., pág. 456. Posteriormente, con ocasión de la reforma de 2010, apuntando que la jurisprudencia había situado el control de razonabilidad en una zona de incertidumbre, GOERLICH PESET, J. M.: “La reforma...”, cit., pág. 277.
} 
los órganos judiciales en el sentido de que no cabía exigir una prueba plena sobre tal "conexión", bastando con una mera argumentación sobre el carácter razonable de los despidos para mejorar la organización empresarial, sin que, además, el control judicial pudiese entrar en valoraciones acerca de si las decisiones empresariales adoptadas eran las más adecuadas para los fines perseguidos o si cabían otras medidas alternativas ${ }^{74}$. Sin embargo, en una línea interpretativa divergente, otras posturas doctrinales y judiciales quisieron ver en dicha referencia a la razonabilidad la remisión a un control judicial más incisivo y reforzado, extrapolando, en buena medida, a esta materia los cánones del control de constitucionalidad. Desde esta perspectiva, el carácter razonable del despido implicaría un control de proporcionalidad como ponderación de los intereses en juego, de modo que la preservación del derecho al trabajo ex art. 35 CE llevaría a valorar las diferentes alternativas en manos del empresario, concibiendo el despido como ultima ratio ${ }^{75}$. De hecho, de forma bastante coetánea a la reforma de 2010 , el TS, en supuestos relativos a despidos por causas productivas, formuló en alguna sentencia un juicio construido en torno a esa ligazón entre el carácter razonable de la medida y la ponderación del derecho constitucional al trabajo, concluyéndose que, a pesar de no estar contemplado en la norma legal, la empresa debía dar prioridad a otras medidas -traslado del trabajador- antes de acometer la decisión extintiva ${ }^{76}$. Asimismo, en la doctrina judicial anterior a la reforma de 2012, se podían encontrar múltiples ejemplos en los que la razonabilidad del despido se identificaba con un control judicial de amplio alcance, que conllevaba entrar en el fondo de las decisiones organizativas adoptadas por el empresario, incluyendo la posibilidad de adoptar medidas menos traumáticas que el despido -vgr. recolocaciones mediante diferentes tipos de movilidad; modificaciones sustanciales de las condiciones de trabajo, etc. $-{ }^{77}$. Es obvio que estos planteamientos no resultaban coherentes con el criterio jurisprudencial antes apuntado, que ha venido negando la obligación empresarial de haber agotado las posibilidades de acomodo del trabajador en la empresa para justificar el despido (véase supra 3.1), así como con la afirmación claramente limitativa del control judicial recogida en alguna otra STS, en la que se puede leer que: "no nos incumbe a los Tribunales de Justicia tratar de hallar otras soluciones organizativas que estimemos más adecuadas sustituyendo la misión que la ley y la realidad económica encomiendan al empresario"78.

De cuanto antecede se colige, como se apuntaba más arriba, que a la hora de eliminar la referencia al juicio de razonabilidad el legislador de 2012 tomó en consideración que el mismo quedaba muy expuesto a diversas y divergentes lecturas, no siempre coincidentes con los objetivos de la reforma. Se evitó, por ello, hacer referencia a un elemento envuelto de una notable indefinición y ambivalencia, como lo pone, en buena medida, de manifiesto el hecho de que ya una inicial juris-

\footnotetext{
${ }^{74}$ Cfr. DEL REY GUANTER, S.: "El despido por causas empresariales en la Ley 35/2010: los nuevos arts. 51 y 52 c) del ET, Relaciones Laborales, no 21, 2010, pág. 7 de la versión de internet. En esta misma línea, analizando los despidos por causas económicas, DESDENDATO BONETE, A.: “La reforma...”, cit., pág. 96; BLASCO PELLICER, A.: "La reforma...”, cit., pág. 58. Asimismo, considerando que la reforma de 2010 trasladaba la idea de que el despido no tenía que ser concebido como ultima ratio, RODRÍGUEZ-PINEERO Y BRAVO FERRER, M.: “La reforma laboral y el dinamismo del contrato de trabajo", Relaciones Laborales, no 21, 2010, pág. 13 de la versión de internet.

${ }^{75}$ Cfr. ALARCÓN CARACUEL, M. R.: "Reformas relativas a la extinción del contrato de trabajo", Actum Social, no 47, 2011, pág. 7 y 8 de la versión de internet. En este mismo sentido, interpretando la reforma de 2010, SJS no 1 Guadalajara 17-3-2011 (Ro 1039/2010). Y tras la reforma de 2012, considerando necesario mantener un juicio de razonabilidad en tal sentido, APARICIO TOVAR, J.: "Las causas del despido basadas en necesidades de funcionamiento de la empresa", Revista de Derecho Social, no 57, 2012, pág. 163 y 164.

${ }^{76}$ STS 29-11-2010 (Ro 3876/2010), declarando la improcedencia del despido. En el mismo sentido se pronunció la STS 16-52011 (Ro 2727/2010), si bien se declaró procedente el despido por entender que el trabajador no cumplió con su carga probatoria relativa a la existencia de vacante adecuada a su categoría profesional.

${ }^{77}$ Cfr., entre otras, STSJ Castilla y León 28-11-1995 (Ro 2203/1995); STSJ País Vasco 12-12-1995 (Ro 2619/1995); STSJ Islas Canarias 6-11-1996 (Ro 655/1996); SSTSJ Comunidad Valenciana 24-7-1998 (Ro 2307/1997) y 11-5-2004 (Ro 509/2004); STSJ Galicia 3-6-2005 (Ro 1449/2005); SSTSJ Cataluña 13-2-2008 (Ro 6869/2007) y 17-9-2010 (Ro 2521/2010); STSJ Aragón 10-32010 (Ro 94/2010).

${ }^{78}$ STS 2-3-2009 (Ro 1605/2008).
} 
prudencia se hubiera referido vagamente a un "juicio de atenimiento del empresario a una conducta razonable, con arreglo a los criterios técnicos de actuación atendidos o atendibles en la gestión económica de las empresa" ", lo que perfectamente podía ser leído como una invitación a que el juez se coloque en la posición del empresario y acabe pronunciándose sobre la base de un criterio de oportunidad acerca de cuáles son las necesidades y alternativas de la empresa ${ }^{80}$. Que la reforma de 2012, al focalizar la atención en la concurrencia de las causas y suprimir otras referencias, ha querido desterrar definitivamente controles judiciales en esta línea, parece algo bastante evidente ${ }^{81}$. Y ello a pesar de que la opinión de un sector de la jurisdicción social ha terminado calando en la propia jurisprudencia del TS que ha mantenido vivo un cierto debate; debate que, sin embargo, por lo que se refiere a los despidos por causas técnicas, no parece por ahora muy trascendente.

De hecho, la cuestión ha quedado reflejada principalmente en sentencias relativas a despidos colectivos acometidos invocando causas económicas y, en un primer momento, el TS pareció ser plenamente consciente de los planteamientos de la reforma, poniendo de relieve que "el legislador de 2012 ha querido (...) que los órganos jurisdiccionales encargados del enjuiciamiento de los despidos colectivos no sustituyan al empresario en la elección de las medidas concretas a adoptar, limitando su control a verificar que las causas alegadas existen, que tienen seriedad suficiente para justificar una reestructuración de los objetivos y de los recursos productivos de la empresa, que no son por tanto un pretexto o excusa para despedir, y que la supresión o amortización de puestos de trabajo acordada es una medida apropiada (o una de las medidas apropiadas) para hacerles frente", de modo tal que no procedería, al "valorar las causas de los despidos económicos, efectuar un juicio de proporcionalidad en el sentido técnico-jurídico de la expresión, el cual presupone una valoración del carácter indispensable de la decisión adoptada, sino un juicio de adecuación más limitado, que compruebe la existencia de la causa o causas alegadas, su pertenencia al tipo legal descrito en el artículo 51 ET, y la idoneidad de las mismas en términos de gestión empresarial en orden a justificar los ceses acordados" 82 .

Con todo, las alusiones a un juicio de razonabilidad y proporcionalidad han seguido presentes en la posterior doctrina del TS, afirmándose que "la novedosa redacción legal incluso pudiera llevar a entender - equivocadamente, a nuestro juicio - la eliminación de los criterios de razonabilidad y proporcionalidad judicialmente exigibles hasta la reforma (...)", pero "contrariamente a esta última posibilidad entendemos, que (...) la remisión que el precepto legal hace a las acciones judiciales y la obligada tutela que ello comporta [art. 24.1 CE], determinan que el acceso a la jurisdicción no pueda sino entenderse en el sentido de que a los órganos jurisdiccionales les compete no sólo emitir un juicio de legalidad en torno a la existencia de la causa alegada, sino también de razonable adecuación entre la causa acreditada y la modificación acordada's3. Y confirmando esta orientación, en otras sentencias el Alto Tribunal ha pretendido ser más explícito sobre el fundamento y la aplicación de estos juicios de razonabilidad y proporcionalidad. El fundamento se hallaría en la necesidad de realizar una interpretación de las causas del despido acomodada a la Constitución y a los compromisos internacionales asumidos por Espańa, de modo tal que en virtud del derecho al trabajo ex art. $35 \mathrm{CE}$, en su vertiente a la estabilidad en el empleo, y de lo previsto en los arts. 4 y 9 del Convenio 158 OIT, en punto a la justificación causal del despido, su control judicial exigiría la aplicación de un juicio de

\footnotetext{
${ }^{79}$ STS 14-6-1996 (Ro 3099/1995).

${ }^{80}$ En esta línea, DURÁN LÓPEZ, F.: “El despido...”, cit. pág. 1105.

${ }^{81}$ Cfr. BLASCO PELLICER, A.: "La extinción...”, cit. pág. 165 y 166. Asimismo, señalando que la reforma de 2012 iría destinada a evitar una interpretación de la razonabilidad como proporcionalidad y, por tanto, un control judicial sobre las alternativas empresariales, DESDENTADO BONETE, A.: "Los despidos económicos tras la reforma de la Ley 3/2012: reflexiones sobre algunos problemas sustantivos y procesales", Actualidad Laboral, n 17, 2012, pág. 3 de la versión de internet.

${ }^{82}$ STS 20-9-2013 (Ro 11/2013).

${ }^{83}$ STS 18-2-2014 (Ro 96/2013); razonamiento reiterado, entre otras, en las SSTS 26-3-2014 ( $\mathrm{R}^{\circ}$ 158/2013) y 21-1-2016 (Ro $144 / 2015)$.
} 
razonabilidad, que "tendria una triple proyección y sucesivo escalonamiento: 1).- Sobre la "existencia" de la causa tipificada legalmente como justificativa de la medida empresarial (...) 2).- Sobre la "adecuación" de la medida adoptada, aunque en su abstracta consideración de que la medida se ajusta a los fines-legales-que se pretenden conseguir, bien de corregir o hacer frente-en mayor o menor grado- a la referida causa. Y3). - Sobre la "racionalidad" propiamente dicha de la medida, entendiendo que este tercer peldaño de enjuiciamiento hace referencia a que han de excluirse por contrarias a Derecho las medidas empresariales carentes de elemental proporcionalidad. Juicio este último -de proporcionalidad-que ha de ser entendido en el sentido de que si bien no corresponde a los Tribunales fijar la precisa «idoneidad» de la medida a adoptar por el empresario ni tampoco censurar su «oportunidad» en términos de gestión empresarial, en todo caso han de excluirse-como carentes de "razonabilidad» y por ello ilícitas-aquellas decisiones empresariales (...) que ofrezcan patente desproporción entre el objetivo legalmente fijado y los sacrificios impuestos a los trabajadores' ${ }^{\prime 24}$. Es cierto que, a la luz de los matices introducidos, la propia doctrina jurisprudencial parece haberse prevenido del riesgo de extralimitar el alcance de unas consideraciones, una vez más, notablemente ambiguas, de modo tal que el juicio proporcionalidad no parece que incluya una valoración judicial de si resultan posible otras medidas alternativas y menos traumáticas que los despidos ${ }^{85}$. Resulta, en todo caso, complejo calibrar el alcance de esta doctrina jurisprudencial, pues, aunque la misma parece haberse presentado como más exigente que la primera doctrina sentada tras la reforma de 2012, del conjunto de pronunciamientos posteriores resulta difícil llegar a una conclusión nítida acerca de cuáles son tales requisitos más exigentes ${ }^{86}$.

Pero, junto con los imprecisos contornos y efectos de estos planteamientos del TS, llama también la atención, a mi juicio, su discutible fundamento, máxime una vez conocida la doctrina del TC que ha avalado la constitucionalidad de la caracterización causal de los estos despidos operada por reforma de 2012. No parece, ciertamente, que la opción del legislador se oponga al contenido del derecho al trabajo en su vertiente individual que, conforme a la doctrina constitucional, comporta el derecho a no ser despedido sin justa causa (SSTC 22/1981 y 192/2003), para lo cual resulta esencial que el legislador ordinario arbitre mecanismos que permitan una reacción adecuada del trabajador frente a la decisión empresarial de prescindir de sus servicios (STC 20/1994). Y, en este sentido, parece difícil negar que, tras la reforma de 2012, el despido ex arts. 51 y 52 c) ET sigue siendo causal, disponiendo el ordenamiento de elementos sustantivos y cauces procesales para someter la decisión empresarial a un efectivo control judicial. Como señaló la STC 8/2015, ante la denuncia de que la supresión legal de la referencia a la razonabilidad de los despidos habría incidido negativamente en dicha causalidad y su efectivo control judicial (arts. 35.1 y $24.1 \mathrm{CE}$ ), una lectura del art. 51 ET no permite afirmar que el mismo "haya consagrado un despido colectivo no causal o ad nutum (...), sino que ha condicionado la decisión extintiva, como ha sucedido desde sus orígenes, a la concurrencia "fundada" de una causa "económica", "técnica", "organizativa" o "productiva", cuyo contenido y alcance delimita, con el objeto de facilitar tanto la aplicación de la norma (...), como el posterior control judicial de la decisión extintiva en función de las circunstancias concurrentes". Además, para el TC "la supresión especifica (...) de la razonabilidad de la decisión extintiva, ni desdibuja las causas extintivas, ni introduce una mayor discrecionalidad empresarial de cara a la adopción de la decisión sino, antes al contrario, suprime espacios de incertidumbre en la interpretación y aplicación de la nor-

${ }^{84}$ STS 17-7-2014 (Ro 32/2014), de la que se hacen eco, entre otras, las SSTS 20-10-2015 (Ro 172/2014) y 11-7-2018 (Ro 467/2017).

${ }^{85}$ De hecho, en la antes citada STS 17-7-2014 (Ro 32/2014) se descarta que el control judicial deba y pueda valorar si la situación económica acreditada por la empresa justificaba un despido colectivo o una suspensión temporal de relaciones laborales, pues tal decisión viene a traducirse en juicio de "oportunidad" que corresponde en exclusiva a la gestión de la empresa. En la misma línea, considerando que la valoración de si caben otras medidas alternativas menos traumáticas es algo que compete a la gestión empresarial, STS 20-7-2016 (Ro 303/2014).

${ }^{86}$ En esta línea, MARTÍN VALVERDE, A.: “Razonabilidad...”, cit., pág. 8-10 
ma generados por unas previsiones legales, tan abiertas en su contenido como abstractas en sus objetivos (...). Y la nueva redacción no otorga mayor espacio a la discrecionalidad empresarial que la anterior en la adopción de una decisión extintiva, sino que, atendiendo a las exigencias derivadas del principio de seguridad juridica (art. 9.3 CE), dota de mayor certidumbre al contenido de la decisión (...) al evitar la realización de juicios de oportunidad y valoraciones hacia el futuro de incierta materialización". Por tanto, si la actual caracterización causal de los despidos ex arts. 51 y 52 c) ET no supone menoscabo del derecho al trabajo ex art. 35.1 CE, no parece haber espacio para una relectura de la misma por parte de la jurisdicción ordinaria a la luz del citado precepto constitucional ${ }^{87}$.

Asimismo, no parece que la actual regulación de las causas de estos despidos se oponga a los imperativos del citado Convenio 158 de la OIT, del que se deriva también la necesidad de una causa justificativa del despido y el derecho del trabajador a recurrir la decisión empresarial ante un órgano neutral facultado para valorar la causa invocada, su prueba, así como otras circunstancias relacionadas con el caso (arts. 4, 8 y 9.1 y 9.2). Como se deduce del análisis efectuado en páginas precedentes, la actual regulación española para nada excluye un control sobre la realidad de la causa esgrimida para despedir y sobre otras circunstancias que puedan denotar un ejercicio abusivo de la facultad extintiva por parte del empresario, respetando, eso sí, el margen de decisión que corresponde al mismo en la gestión de la empresa. No parece, en este sentido, que nuestra regulación vigente se oponga a las exigencias del Convenio 158 de la OIT por el hecho de incorporar una caracterización de las causas del despido que excluye que el juez tenga que valorar la razonabilidad y proporcionalidad del despido, entendido ello como una valoración sobre su adecuación para la consecución de determinados fines o incluso, según se vio, sobre la posibilidad de adoptar medidas alternativas al despido. A tal conclusión cabe llegar a partir de una lectura cabal de los preceptos del Convenio 158 antes citados; conclusión que se ve, además, reforzada a la luz del art. 9.3 del propio Convenio que referido particularmente a los despidos por "razones basadas en necesidades de funcionamiento de la empresa" ${ }^{88}$, como es el caso de los despidos ex art 52 c) ET, y partiendo del inexorable control sobre la realidad de la causa, parece otorgar a cada legislación nacional un amplio margen de actuación para determinar el alcance del control judicial en lo referente a si la causa acreditada es "suficiente" para justificar la terminación de la relación laboral ${ }^{89}$. El propio TS se ha hecho eco en alguna ocasión de este art. 9.3 del Convenio 158 de la OIT para intentar acotar el oscuro alcance de los juicios de razonabilidad y proporcionalidad ${ }^{90}$.

Dicho lo anterior, mayor fundamento tienen, a mi modo de ver, otras referencias que también recoge la jurisprudencia para abogar por el citado de control de razonabilidad de los despidos, aludiendo a "principios generales de Derecho Común en el ejercicio de los derechos subjetivos, y muy particularmente tanto el que impone que el mismo haya de llevarse a cabo "conforme a las exigencias de la buena fe» [art. 7.1 CC], cuanto el que prohibe el "abuso del derecho o el ejercicio antisocial del mismo» [art. 7.2]' '.1. En este sentido, en páginas precedentes ya se apuntó que estos principios constituyen límites internos del poder extintivo del empresario, que en el caso particular de los despidos

\footnotetext{
${ }^{87}$ En este sentido, GOERLICH PESET, J. M.: "El problemático fundamento positivo del control de razonabilidad de las causas del despido colectivo", en (AAVV): Comentarios al Estatuto de los Trabajadores: libro homenaje a Tomás Sala Franco, Valencia, Tirant lo Blanch, 2016, pág. 1013.

${ }^{88}$ Dispone el citado art. 9.3 que: "En los casos en que se invoquen para la terminación de la relación de trabajo razones basadas en necesidades de funcionamiento de la empresa, establecimiento o servicio, los organismos mencionados en el artículo 8 del presente Convenio (órganos neutrales antes los que impugnar el despido) estarán facultados para verificar si la terminación se debió realmente a tales razones, pero la medida en que esos organismos estarán facultados también para decidir si esas razones son suficientes para justificar la terminación deberá determinarse por los métodos de aplicación mencionados en el artículo 1 de este Convenio". Este artículo 1 alude, por su parte, a las legislaciones nacionales como principal vía para implementar las disposiciones del Convenio.

${ }^{89}$ En este sentido, GOERLICH PESET, J. M.: “El problemático...”, cit. págs. 1013 y 1014.

${ }^{90}$ STS 24-11-2015 (Ro 1681/2014).

${ }^{91}$ Entre otras, STS 17-7-2014 (Ro 32/2014), 20-10-2015 (Ro 172/2014) y 11-7-2018 (Ro 467/2017).
} 
por causas técnicas permiten que el juez exija acreditar no sólo el cambio técnico sino también su repercusión sobre el puesto del trabajador o trabajadores despedidos. Pero al margen de esta concreta función integradora sobre el alcance de la fiscalización judicial, no parece que tales principios generales justifiquen un control judicial que, yendo más allá de valorar la razonabilidad del despido desde esta perspectiva de la relación causa-efecto entre la causa probada y el concreto o concretos trabajadores despedidos, se proyecte sobre otras valoraciones diversas concernientes a la gestión de las empresas (origen o motivo del cambio técnico-organizativo decidido, fines perseguidos con el cambio y los despidos, posibilidad de adoptar otras medidas menos traumáticas, selección del trabajador despedido entre los afectados por la causa, etc.). De hecho, al menos en la reciente doctrina judicial relativa a los despidos invocando causas técnicas, pese a no ser infrecuente la referencia a la doctrina jurisprudencial "preservadora" de los juicios de razonabilidad y proporcionalidad, no parece que ello esté comportando, salvo excepciones, un control judicial de muy diverso signo y alcance al esbozado en el presente trabajo ${ }^{92}$.

\section{Reflexión final}

El marco jurídico -legal e interpretativo- vigente en punto al despido por causas técnicas se presenta menos refractario, en comparación con regímenes anteriores, a la introducción de cambios tecnológicos en la empresa que impliquen ajustes del volumen de empleo en la misma. Y, a mi modo de ver, cualquier nueva intervención normativa y/u orientación jurisprudencial que pudiera evocar a una suerte de "neoludismo" seguramente esté abocada al fracaso en varios sentidos, dada la inevitable expansión de la denominada digitalización de la economía y del empleo. Probablemente, para grandes empresas solventes el riesgo de tener que hacer frente a una indemnización por despido improcedente sea un escaso desincentivo frente a sus proyectos "tecnológicos" "33, sin perjuicio de los efectos penalizadores que intervenciones legales o interpretaciones en el sentido apuntado podrían tener para la competitividad y productividad de un conjunto más amplio de empresas y, por tanto, para la economía nacional, máxime en el contexto de una economía globalizada ${ }^{94}$, amén de poder introducir un factor distorsionador de la competencia entre empresas asentadas en un sector o rama de actividad, que quieren introducir cambios para adaptarse a los progresos tecnológicos y ganar en competitividad, y las nuevas empresas que "irrumpen" ya adaptadas y muy avanzadas tecnológicamente $^{95}$. Nótese que, al decir de los expertos, uno de los desequilibrios crónicos de la economía espańola radica en el débil crecimiento de la productividad, lo que supone un lastre para diversas variables de suma importancia para la economía de un Estado del Bienestar, tales como el crecimiento de los salarios, los ingresos públicos para financiar las políticas sociales, así como un mayor consumo y nuevas inversiones que generen más empleo; de ahí la conveniencia de que, junto al mantenimiento e impulso de diversas reformas, la economía espańola sepa aprovechar las ventajas en términos de productividad de la actual revolución digital ${ }^{96}$. Y entre las medidas acompañantes

${ }^{92}$ Cfr., entre otras, STSJ Andalucía 17-5-2016 (Ro 1385/2015); STSJ Cataluña 9-6-2016 (Ro 2167/2016); STSJ Galicia 9-52017 (Ro 1038/2017); STSJ Comunidad Valenciana 23-10-2018 (Ro 2587/2018); STSJ Cantabria 31-10-2018 (Ro 590/2018); STSJ Madrid 7-2-2019 (Ro 933/2018); STSJ Andalucía 14-2-2019 (Ro 2006/2018); STSJ Madrid 7-10-2019 (Ro 775/2019).

${ }^{93}$ En esta línea, al hilo de la SJS de Las Palmas antes comentada, MERCADER UGUINA, J. R.: "Despido...”, cit.

${ }^{94}$ En esta línea, reflexionando sobre el papel del ordenamiento laboral ante la digitalización, CRUZ VILLALÓN, J.: "Las transformaciones...”, cit. pág. 27 y 31.

${ }^{95}$ En este sentido, DURÁN LÓPEZ, F. “¿Ludismo judicial?”, en el blog del Centro de Estudios Garrigues, disponible en: https://blog.centrogarrigues.com/derecho-empresarial/ludismo-judicial/ (consulta 21-5-2020).

${ }^{96}$ Cfr. DOMÉNECH, R.: "El puzle de la productividad en España", BBVA Research, 2 abril de 2019, disponible en: https:// www.bbvaresearch.com/wp-content/uploads/2019/04/RafaelDomenech_VP_ESP.pdf. 
del inevitable cambio tecnológico en curso cobran, quizá más que nunca, especial importancia unas políticas educativas y unas políticas activas de empleo realmente eficaces, que faciliten las inserciones y transiciones laborales ${ }^{97}$.

${ }^{97}$ Cfr. GOERLICH PESET, J. M.: “¿Repensar...”, cit., pág. 179; CRUZ VILLALÓN, J.: “Las transformaciones...”, cit. pág. 34. 